\title{
CARACTERIZAÇÃO DE ÓXIDOS DE FERRO DE SOLOS DO AMBIENTE TABULEIROS COSTEIROS ${ }^{(1)}$
}

\author{
Marcelo Metri Correa ${ }^{(2)}$, João Carlos Ker ${ }^{(3)}$, Vidal Barrón ${ }^{(4)}$, \\ Maurício Paulo Ferreira Fontes ${ }^{(3)}$, José Torrent ${ }^{(4)}$ \& Nilton Curi ${ }^{(5)}$
}

\section{RESUMO}

Vários têm sido os trabalhos contemplando a gênese e as conseqüências da coesão em Argissolos e Latossolos nos tabuleiros costeiros e interioranos. Poucos, entretanto, sãos os estudos referentes à mineralogia da fração argila, sobretudo aqueles referentes à uma completa caracterização dos óxidos de Fe. $O$ objetivo deste trabalho foi estudar as características químicas e cristalográficas dos óxidos de Fe de solos vermelhos e amarelos, derivados de sedimentos da Formação Barreiras ou de materiais do Pré-Cambriano, que ocorrem na região dos Tabuleiros Costeiros ou Interioranos de diversos Estados do País. Para tanto, foram realizadas análises de difratometria de raios X, em amostras concentradas de óxidos de Fe, extrações sucessivas com DCB e extração com oxalato de amônio em amostras de argila, caracterização espectral por ERD, estimativa das propriedades cristalográficas da goethita, quantificação da substituição isomórfica de $\mathrm{Fe}$ por $\mathrm{Al}$ e microscopia eletrônica de transmissão. De acordo com os resultados obtidos, concluiu-se que: (a) a goethita mostrou-se como óxido de Fe predominante em todos os solos, mesmo naqueles com matizes 2,5YR, cujo valor de hematita foi inferior a 2,5 dag kg-1 de argila; (b) os valores de substituição isomórfica de Fe por $\mathrm{Al}$ das goethitas foram de três a seis vezes superiores aos da hematita, bem como não condizem com os valores estimados por modelos matemáticos, propostos pela literatura científica, indicando a necessidade de realização de novos estudos, a fim de demonstrar a existência de relações entre os parâmetros cristalográficos de goethitas naturais e suas propriedades químicas; (c) os resultados obtidos por difratometria de raios $\mathrm{X}$ e análise de dissolução química revelaram que as goethitas dos solos são distintas daquelas citadas, até o momento, na literatura; e (d) a posição das bandas obtidas nos espectros de espectroscopia de refletância difusa apresentou correlação com algumas propriedades cristalográficas das goethitas

\footnotetext{
(1) Trabalho extraído da Tese de Doutorado do primeiro autor, em Solos e Nutrição de Plantas pela Universidade Federal de Viçosa - UFV. Recebido para publicação em junho de 2007 e aprovado em fevereiro de 2008.

${ }^{(2)}$ Professor do Departamento de Agronomia, Universidade Federal Rural de Pernambuco - UFRPE. CEP 552986-280 Garanhuns (PE). Bolsista CAPES/PDEE. E-mail: marcelometri@yahoo.com

${ }^{(3)}$ Professor do Departamento de Solos, Universidade Federal de Viçosa - UFV. Av. PH Rolfs s/n, CEP 36570-000 Viçosa (MG). Emails: jcker@ufv.br; mpfontes@ufv.br

(4) Professor do Departamento de Ciencias y Recursos Agricolas y Florestales da Universidad de Cordoba, Espanha. E-mail: torrent@uco.es

(5) Professor do Departamento de Ciência do Solo, Universidade Federal de Lavras - DCS/UFLA. Caixa Postal 37, CEP 37200-000 Lavras (MG). E-mail: niltcuri@ufla.br
} 
dos solos estudados, mostrando-se ser uma técnica promissora para o estudo dos óxidos de ferro.

Termos de indexação: Brasil, goethita, hematita, substituição isomórfica, Formação Barreiras.

\title{
SUMMARY: CHARACTERIZING IRON OXIDES FROM COASTAL AND CENTRAL PLAIN SOILS
}

\begin{abstract}
There have been several papers in the literature studying the genesis and consequences of particles cohesion in Argisols (Ultisols) and Latosols (Oxisols) from the Brazilian Inner and Coastal Plains. Just a few, however, provide insights into the clay fraction mineralogy, specially, the iron oxides complete characterization. The objective of this study was to investigate the chemical and crystallographic characteristics of iron oxides in red and yellow soils derived from the sediments of the Barreiras Formation or Pre-Cambrian rocks in the region of the coastal and central plateaus of several Brazilian states. The following research procedures were used: $X$-ray diffraction analyses in iron oxide-concentrated samples; successive extractions with $C B D$, and ammonium oxalate extraction in clay samples; spectral characterization by DRS; estimation of the crystallographic properties of goethite; quantification of isomorphic substitution of $\mathrm{Fe}$ for $\mathrm{Al}$; and electronic transmission microscopy. According to the results, the following conclusions were drawn: (a) goethite was the predominant iron oxide in all soils, even in those with $2.5 Y R$ hues, of which the hematite value was below $2.5 \mathrm{dag} \mathrm{kg}{ }^{-1}$ clay; (b) the values of the isomorphic Fe substitution by $\mathrm{Al}$ were 3 to 6 times higher for goethites than for hematites. These values did not agree with those estimated by mathematical models proposed in the scientific literature, which indicates the need for further studies of the relationships between crystallographic parameters of natural goethites and their chemical properties; (c) the results obtained by $X$ ray diffractometry and chemical dissolution analysis revealed that the goethites in the soils differ from those cited, to date, in the literature; (d) the position of the bands obtained in the spectra of the diffuse reflectance spectroscopy was correlated with some crystallographic properties of the goethites in the soils, indicating a promising technique for the study of iron oxides.
\end{abstract}

Index terms: Brazil, goethite, hematite, isomorphous substitution, Barreiras Formation.

\section{INTRODUÇÃO}

Os óxidos de $\mathrm{Fe}$, principalmente hematita e goethita, estão intimamente relacionados com os fenômenos de estruturação e agregação dos solos, podendo conferir-lhes características desejáveis, tais como maior permeabilidade à água e maior resistência à erosão. Podem, ainda, estar vinculados a outras propriedades dos solos, como a cor, capacidade de troca catiônica e aniônica (CTC e CTA), fixação de P e de metais pesados, dentre outras. Dentre essas, a cor mostra-se a mais visível e utilizada para caracterizar e diferenciar os solos, onde as cores vermelhas e amarelas resultam da presença de hematita e goethita, respectivamente.

Os óxidos de $\mathrm{Fe}$ apresentam grande variação na cor, na forma e na própria constituição, que podem estar relacionadas com os ambientes de sua formação (Fey \& Dixon, 1981; Schulze, 1984; Schwertmann \& Carlson, 1994). Além de Fe, oxigênio e hidrogênio, esses minerais podem apresentar o $\mathrm{Al}$. De acordo com Schwertmann \& Taylor (1989) e Cornell \&
Schwertmann (1996), a substituição de $\mathrm{Fe}$ por $\mathrm{Al}$ é um fenômeno natural comum nas goethitas e hematitas, podendo constituir mais uma regra que uma exceção na natureza, principalmente para as goethitas de clima tropical.

Vários trabalhos com óxidos de Fe têm sido realizados no Brasil, mas poucos abrangem o domínio geomorfológico dos Tabuleiros Costeiros. Essa região é dominada por Latossolos e Argissolos Amarelos, principalmente derivados dos sedimentos argiloarenosos da Formação Barreiras. Todos esses solos têm, em comum, baixo teor de óxido de Fe em sua constituição, sendo esta, talvez, a principal causa de poucos estudos dirigidos a esses minerais nesse ambiente. Contudo, no ambiente dos tabuleiros costeiros, podem ocorrer pequenas áreas com solos avermelhados (Latossolos e Argissolos), com teor de óxidos de $\mathrm{Fe}$ mais elevado, sugerindo material de origem distinto, influenciado por rochas do PréCambriano, que embasam esta formação sedimentar.

O objetivo deste trabalho foi estudar as características químicas e cristalográficas dos óxidos 
de Fe de solos vermelhos e amarelos, derivados de sedimentos terciários ou de materiais do PréCambriano, em regiões de tabuleiros costeiros ou interioranos de diversos estados brasileiros.

\section{MATERIAL E MÉTODOS}

\section{Descrição dos locais de coleta das amostras de solo}

Foram coletadas, em trincheiras, amostras do horizonte B de 13 perfis de solo, classificados como Argissolo Vermelho, Argissolo Amarelo, Latossolo Amarelo e Espodossolo, localizados em diferentes locais da região dos Tabuleiros Costeiros e, apenas um, na região Norte do Brasil (Figura 1). Nos perfis localizados no Sul da Bahia e Norte do Espírito Santo, mais especificamente, nas regiões de Teixeira de Freitas e Mucurici, foram coletados dois horizontes por perfil (BA e $\mathrm{Bt}_{3}$ ), a fim de identificar diferenças nas propriedades cristaloquímicas dos óxidos em profundidade. Para os demais, coletou-se apenas o horizonte $\mathrm{Bt}_{2}$ (Quadro 1). Os perfis $\mathrm{P} 1$ a $\mathrm{P} 6$ foram coletados em duas topossequências, conforme figura 1 .

As amostras foram coletadas, procurando-se abranger diferentes condições climáticas, desde locais com déficit pronunciado e estação seca bem definida (Mucurici), até locais com alta precipitação (Manaus). De acordo com a classificação de Köppen, o clima da região de Mucurici (Norte do Espírito Santo) é do tipo Aw, caracterizado pela presença de um período seco mais longo que a área anterior, com temperatura superior a $20^{\circ} \mathrm{C}$ (Siqueira et al., 2004). Já em Manaus, o clima da região é do tipo Af, caracterizado por apresentar temperatura do mês mais frio sempre superior a $18^{\circ} \mathrm{C}$, precipitação pluvial do mês mais seco superior a $60 \mathrm{~mm}$ e precipitação média anual de $2.400 \mathrm{~mm}$. Nas demais regiões de coleta dos perfis, o clima mostra-se intermediário a estas condições (Quadro 1).

Geologicamente, nos locais de coleta dos perfis predominam sedimentos Cenozóicos da Formação Barreiras, constituídos de materiais argilosos ou argilo-arenosos com espessura variada. Foram coletados, também, solos desenvolvidos a partir de biotita e, ou, hornblenda-granada gnaisses do Complexo Paraíba do Sul - Pré-Cambriano, que ocasionalmente afloram, influenciando as formas do modelado (DNPM, 1984; Silva et al., 1987) (Quadro 1). O perfil P13 foi coletado em sedimentos argilosos da Formação Alter-do-Chão (Cretáceo Superior).

\section{Análises químicas}

Foram realizadas cinco extrações sucessivas com ditionito-citrato-bicarbonato (DCB) e uma única extração com oxalato ácido de amônio em materiais de argila, conforme método propostos por Mehra \& Jackson (1960) e Schwertmann (1973), respectivamente. Nos extratos, foram determinados os elementos $\mathrm{Al}$ e Fe por espectrometria de absorção atômica.
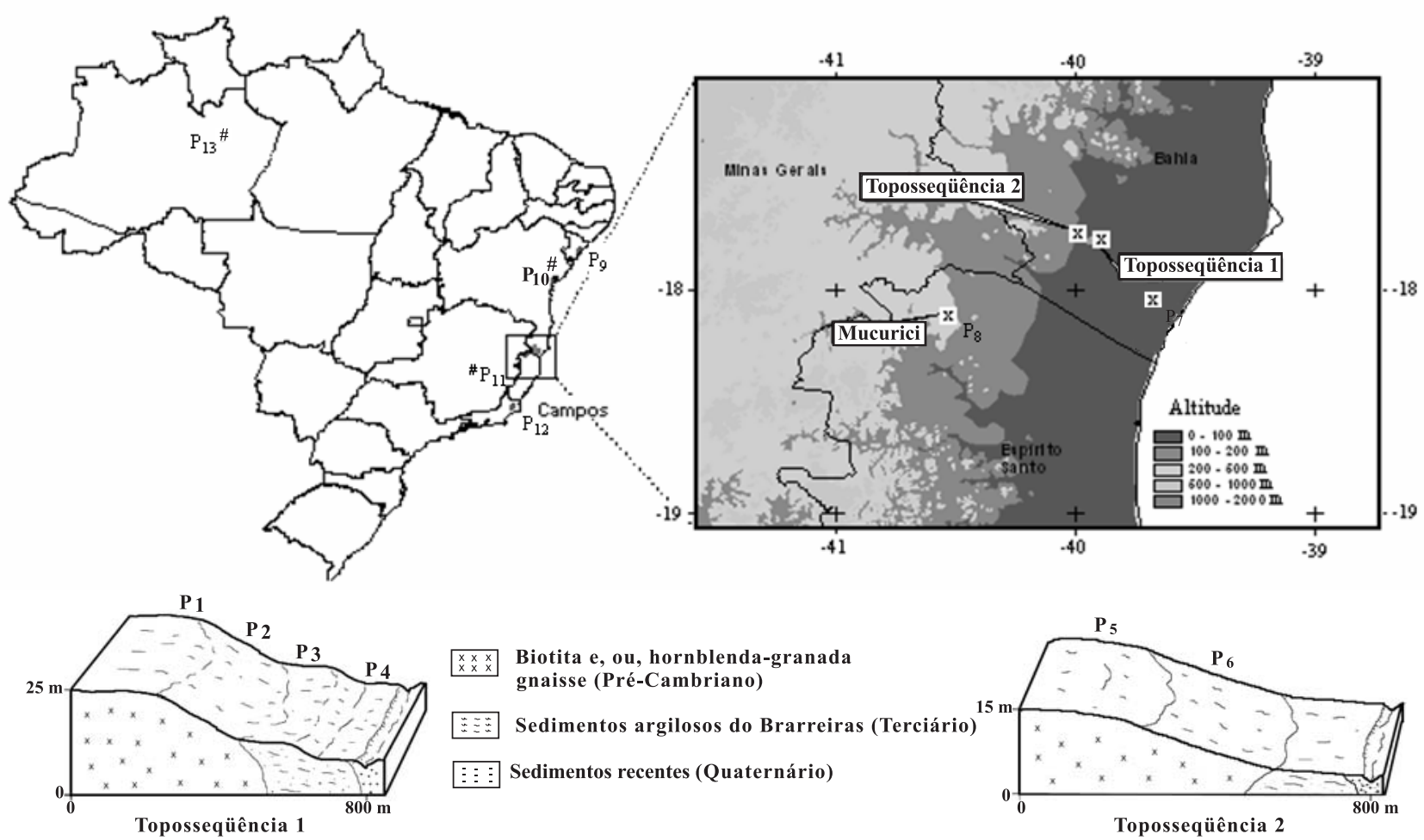

Figura 1. Localização dos perfis coletados e representação de suas toposseqüências. 
Quadro 1. Classificação, localização e material de origem dos solos estudados

\begin{tabular}{|c|c|c|c|c|}
\hline Perfil & Hor. & Classificação & Local & Material de origem \\
\hline $\mathrm{P}_{1}$ & $\begin{array}{l}\mathrm{BA} \\
\mathrm{Bt}_{3}\end{array}$ & $\begin{array}{l}\text { Argissolo Vermelho eutrófico } \\
\text { latossólico }\left(\mathrm{PV}_{1}\right)\end{array}$ & Teixeira de Freitas - BA & $\begin{array}{l}\text { Gnaisse e granitos do Pré- } \\
\text { Cambriano }\end{array}$ \\
\hline $\mathrm{P}_{2}$ & $\begin{array}{l}\mathrm{BA} \\
\mathrm{Bt}_{3}\end{array}$ & $\begin{array}{l}\text { Argissolo Amarelo eutrocoeso típico } \\
\left(\mathrm{PA}_{1}\right)\end{array}$ & Teixeira de Freitas - BA & $\begin{array}{l}\text { Gnaisse e granitos do Pré- } \\
\text { Cambriano }\end{array}$ \\
\hline $\mathrm{P}_{3}$ & $\begin{array}{l}\mathrm{BA} \\
\mathrm{Bt}_{3}\end{array}$ & $\begin{array}{l}\text { Argissolo Amarelo distrocoeso típico } \\
\left(\mathrm{PA}_{2}\right)\end{array}$ & Teixeira de Freitas - BA & $\begin{array}{l}\text { Sedimentos argilo-arenosos do } \\
\text { Barreiras }\end{array}$ \\
\hline $\mathrm{P}_{4}$ & $\begin{array}{l}\mathrm{BA} \\
2 \mathrm{Cxf}_{2}\end{array}$ & $\begin{array}{l}\text { Argissolo Amarelo distrocoeso } \\
\text { fragipânico }\left(\mathrm{PA}_{3}\right)\end{array}$ & Teixeira de Freitas - BA & $\begin{array}{l}\text { Sedimentos argilo-arenosos do } \\
\text { Barreiras }\end{array}$ \\
\hline $\mathrm{P}_{5}$ & $\begin{array}{l}\mathrm{BA} \\
\mathrm{Bt}_{2}\end{array}$ & $\begin{array}{l}\text { Argissolo Amarelo eutrocoeso típico } \\
\left(\mathrm{PA}_{4}\right)\end{array}$ & Teixeira de Freitas - BA & $\begin{array}{l}\text { Gnaisse e granitos do Pré- } \\
\text { Cambriano }^{(1)}\end{array}$ \\
\hline $\mathrm{P}_{6}$ & $\begin{array}{l}\mathrm{BA} \\
\mathrm{Bt}_{3}\end{array}$ & $\begin{array}{l}\text { Argissolo Vermelho eutrófico } \\
\text { latossólico }\left(\mathrm{PV}_{2}\right)\end{array}$ & Teixeira de Freitas - BA & $\begin{array}{l}\text { Gnaisse e granitos do Pré- } \\
\text { Cambriano }^{(1)}\end{array}$ \\
\hline $\mathrm{P}_{7}$ & $\begin{array}{l}\mathrm{Bhs}_{1} \\
2 \mathrm{Cx}_{2}\end{array}$ & $\begin{array}{l}\text { Espodossolo Humilúvico órtico } \\
\text { fragipânico (ES) }\end{array}$ & Teixeira de Freitas - BA & $\begin{array}{l}\text { Sedimentos argilo-arenosos do } \\
\text { Barreiras }\end{array}$ \\
\hline $\mathrm{P}_{8}$ & $\begin{array}{l}\mathrm{Bt}_{1} \\
\mathrm{Bt}_{3}\end{array}$ & $\begin{array}{l}\text { Argissolo Amarelo distrocoeso típico } \\
\left(\mathrm{PA}_{5}\right)\end{array}$ & Mucurici - ES & $\begin{array}{l}\text { Sedimentos argilo-arenosos do } \\
\text { Barreiras }\end{array}$ \\
\hline $\mathrm{P}_{9}$ & $\mathrm{Bt}_{2}$ & $\begin{array}{l}\text { Argissolo Amarelo distrófico típico } \\
\left(\mathrm{PA}_{6}\right)\end{array}$ & Aracajú - SE & $\begin{array}{l}\text { Sedimentos argilo-arenosos do } \\
\text { Barreiras }\end{array}$ \\
\hline $\mathrm{P}_{10}$ & $\mathrm{Bt}_{2}$ & $\begin{array}{l}\text { Argissolo Amarelo distrófico típico } \\
\left(\mathrm{PA}_{7}\right)\end{array}$ & Vera Cruz - BA & $\begin{array}{l}\text { Sedimentos argilo-arenosos do } \\
\text { Barreiras }\end{array}$ \\
\hline $\mathrm{P}_{11}$ & $\mathrm{Bt}_{2}$ & $\begin{array}{l}\text { Argissolo Amarelo distrófico típico } \\
\left(\mathrm{PA}_{8}\right)\end{array}$ & Cruz das Almas - BA & $\begin{array}{l}\text { Sedimentos argilo-arenosos do } \\
\text { Barreiras }\end{array}$ \\
\hline $\mathrm{P}_{12}$ & $\mathrm{Bt}_{2}$ & $\begin{array}{l}\text { Argissolo Amarelo distrófico típico } \\
\left(\mathrm{PA}_{9}\right)\end{array}$ & Campos - RJ & $\begin{array}{l}\text { Sedimentos argilo-arenosos do } \\
\text { Barreiras }\end{array}$ \\
\hline $\mathrm{P}_{13}$ & $\mathrm{Bw}_{2}$ & $\begin{array}{l}\text { Latossolo Amarelo distrófico típico } \\
\left(\mathrm{LA}_{1}\right)\end{array}$ & Manaus - AM & $\begin{array}{l}\text { Sedimentos argilo-arenosos do } \\
\text { Alter-do-Chão }\end{array}$ \\
\hline
\end{tabular}

${ }^{(1)}$ Complexo Paraíba do Sul - Pré-Cambriano (DNPM, 1984).

\section{Análises mineralógicas}

\section{Preparação das amostras}

Amostras concentradas de óxidos de Fe foram obtidas por dissolução seletiva dos materiais silicatados em amostras de argila, utilizando-se solução de $\mathrm{NaOH} 5 \mathrm{~mol} \mathrm{~L}^{-1}$, de acordo com Kämpf \& Schwertmann (1982). Após este tratamento, os materiais foram liofilizados.

\section{Identificação dos componentes por difratometria de raios $\mathrm{X}$}

A identificação dos componentes dos concentrados de óxidos de Fe foi realizada por difratometria de raios X (DRX), em aparelho SIEMENS D-5000 com radiação $\mathrm{CoK} \alpha$, monocromador de grafite e operado a $40 \mathrm{kV}$ e $25 \mathrm{~mA}$. As amostras foram trituradas em almofariz de ágata, juntamente com $5 \%$ de $\mathrm{NaCl}$
(MERCK ACS, ISO PA), utilizado como padrão interno. O conjunto foi montado em suporte de vidro, após pressão suave da amostra sobre papel rugoso, de forma a minimizar a orientação preferencial das partículas. As irradiações variaram de 15 a $80^{\circ} 2 \theta$, com intervalo de $0,02^{\circ} 2 \theta$ para cada seis segundos. Vale destacar que foi mantido o mesmo suporte para todas as amostras analisadas, a fim de evitar possíveis alterações dos espectros (largura ou intensidade de picos) relacionadas com a mudança da porta-amostra.

\section{Análise quantitativa da hematita e da goethita}

As técnicas de extração química por DCB e espectroscopia de refletância difusa (ERD) foram utilizadas, conjuntamente, em amostras de argila para a determinação dos teores de hematita e goethita. A extração por DCB foi realizada para obtenção do teor 
total de Fe na forma de óxido, e a ERD, para determinação da relação hematita/(hematita + goethita).

Os espectros de ERD das amostras, previamente triturados em almofariz de ágata até não perceber alteração da coloração, foram registrados no intervalo de comprimento de onda de 300 a $2500 \mathrm{~nm}$ (faixa do visível e infravermelho) em um VARIAN, modelo CARY 5000, com esfera integradora acoplada de $110 \mathrm{~mm}$ de diâmetro, sendo usados como valor de referência para o branco (padrão), aqueles obtidos em Teflon (AVIAN Technologies Dried and Blended ATPTFE 500 Powder). Os espectros de reflectância obtidos foram transformados em formato ASCII e analisados por meio de uma série de programas BASIC-DOS. Dessa forma, obteve-se a função de Kubelka-MunK $\left[\mathrm{f}(\mathrm{R})=(1-\mathrm{R})^{2} / 2 \mathrm{R}\right]$, bem como sua respectiva segunda derivada (Kosmas et al., 1984; Scheinost et al., 1998). Nos espectros da segunda derivada, determinaram-se as amplitudes de bandas associadas aos comprimentos de onda entre 420 e $450 \mathrm{~nm}$ e entre 530 e $570 \mathrm{~nm}$, relacionados com a goethita $\left(\mathrm{A}_{\mathrm{Gt}}\right)$ e hematita $\left(\mathrm{A}_{\mathrm{Hm}}\right)$, que foram utilizados para a determinação da relação hematita/(hematita + goethita).

Na determinação dos conteúdos de hematita e goethita, também foi utilizada a percentagem de substituição isomórfica por Al. Os cálculos foram realizados, conforme procedimento descrito no software ALOCA (Moura Filho et al., 1995). A quantidade de $\mathrm{Al}$ presente na estrutura das goethita (solos amarelos) foi obtida, por procedimentos químicos. Estimou-se o uso da hematita por meio da equação proposta por Schwertmann \& Carlson (1994) que utiliza a dimensão a, obtida do espectro de DRX (maiores detalhes no item 2.5).

\section{Estimativa da dimensão média do cristalito (DMC) e microtensões $\left(\sqrt{ }<\mathrm{e}^{2}>\right)$}

Para estimar a dimensão média dos cristais de goethitas (DMC) e de suas imperfeições estruturais $\left(\sqrt{ }<\mathrm{e}^{2}>\right)$, foram utilizados procedimentos matemáticos de deconvolução da largura de picos específicos dos espectros de DXR, obtidos em amostras de concentrados de óxidos de Fe. Foram utilizados os modelos propostos por Henke et al. (1978) e Keijser et al. (1983), e os planos cristalográficos (110), (111), (020) e (021), referidos neste trabalho como $\mathrm{Gt}_{110}, \mathrm{Gt}_{111}, \mathrm{Gt}_{020}$ e $\mathrm{Gt}_{021}$. O pico $\mathrm{Gt}_{130}$ foi desconsiderado graças à dificuldade na determinação exata de seus componentes de Gauss e de Cauchy ( $\eta$ ) (utilizado para o cálculo do $\mathrm{DMC}_{\mathrm{a}}$ ), uma vez que se mostrava parcialmente sobreposto pelo pico $\mathrm{Hm}_{104}$ (plano 104 da hematita), nas amostras de coloração avermelhada ou vermelho-amarelada. Utilizaram-se o software RIETICA e a função de ajuste de forma do reflexo pseudo-voigt. O efeito instrumental foi removido, utilizando-se um espectro padrão, nesse caso do quartzo. A DMC dos cristalitos na direção dos eixos $a$ e $b$ foi obtida por meio das equações

$$
D M C_{a}=\frac{1,0954 D M C_{110}+1,8880 D M C_{111}}{2} ; D M C_{b}=\frac{D M C_{020}+1,9305 D M C_{021}}{2}
$$

\section{Decomposição dos espectros de espectro- fotometria de refletância difusa}

Os espectros de ERD foram decompostos, utilizando-se seis equações Gaussianas, a fim de determinar as posições das bandas compreendidas entre os comprimentos de ondas 300 e $1.400 \mathrm{~nm}$.

$$
f[R(E)]=\sum_{i=1}^{n} \frac{h_{i}}{\exp \left[\frac{E-E_{i}}{L M A_{i}}\right]^{2} 4 \ln (2)}
$$

em que, $R$ é a refletância; $E$, a energia em comprimento de onda $(\mathrm{nm}) ; h_{i}$, a altura a ${ }^{\text {th }}$ banda de absorção; $E_{i}$, a energia média (nm) da ith banda (posição da banda); e $L M A_{i}$, a largura a meia altura da $i^{\text {th }}$ banda $(\mathrm{nm})$.

Os espectros foram, primeiramente, transformados por meio da função de Kubelka-MunK $\left[\mathrm{f}(\mathrm{R})=(1-\mathrm{R})^{2} /\right.$ 2R]. Foi utilizado o método de interpolação não-linear Quase-Newton. Os valores de $\mathrm{R}^{2}$ foram todos superiores a 99,90\%. As estimativas iniciais dos parâmetros das equações Gaussianas foram realizadas em planilha de cálculo EXCEL.

\section{Substituição isomórfica do Fe por $\mathrm{Al}$ (SI)}

A substituição de $\mathrm{Fe}$ por $\mathrm{Al}$, em óxidos de $\mathrm{Fe}$, foi realizada em amostras concentradas de óxidos de Fe e em argila total. Para ambos os casos, antes do cálculo da SI, os valores de $\mathrm{Al}_{\mathrm{DCB}}$ e $\mathrm{Fe}_{\mathrm{DCB}}$ foram previamente corrigidos, por meio da subtração do $\mathrm{Al}_{\mathrm{CB}}$ ou $\mathrm{Al}_{\mathrm{OX}} \mathrm{e}$ $\mathrm{Fe}_{\mathrm{OX}}$ ou $\mathrm{Fe}_{\mathrm{CB}}$, evitando possíveis interferências de outras fontes indesejadas de $\mathrm{Al}$ e $\mathrm{Fe}$, como formas amorfas $\mathrm{Fe}$ ou $\mathrm{Al}$, aluminossilicatos de baixa cristalinidade e gibbsita (Curi, 1983; Fontes \& Weed, 1991).

No primeiro caso, $5 \mathrm{mg}$ de material foram postos, juntamente, com $7 \mathrm{~mL}$ da solução de citratobicarbonato e $1 \mathrm{~g}$ de ditionito de $\mathrm{Na}$, em tubos de centrífuga. $\mathrm{O}$ conjunto permaneceu sob agitação por $24 \mathrm{~h}$ a 150 oscilações por minuto em ambiente isotérmico $\left(25^{\circ} \mathrm{C}\right)$ e foi posteriormente, aquecido a $60^{\circ} \mathrm{C}$ por $1 \mathrm{~h}$ em banho-maria. Esse procedimento foi repetido mais uma vez e, finalmente, o conjunto foi centrifugado para obtenção da solução, na qual foram determinados o Fe e Al. O resíduo foi lavado por duas vezes com etanol e digerido com $2 \mathrm{~mL}$ de $\mathrm{HCl}$ concentrado, em banhomaria aquecido a $50^{\circ} \mathrm{C}$ por $2 \mathrm{~h}$, para a determinação do Fe residual. Juntamente e com o objetivo de eliminar possíveis contribuições de $\mathrm{Al}$ derivado da digestão de aluminossilicatos amorfos, em outro conjunto de amostra, foram realizadas extrações com citratobicarbonato e determinado o conteúdo de $\mathrm{Al}$.

A determinação da SI nos concentrados foi também realizada, utilizando-se os espectros de difratometria de raios X. Para isso, aplicaram-se as equações propostas por Schulze (1984), para as goethitas, e por Schwertmann \& Carlson (1994), para as hematitas, 
que utilizam como parâmetros, os valores da dimensão da célula unitária $c$ (goethita) e a (hematita), obtidos após o refinamento de suas estruturas, de acordo com Rietveld (1969), utilizando o software RIETICA (Hunter \& Howard, 2000) e a base de dados cristaligráficos do MINCRYST (www.database.iem.ac.ru) da goethita, hematita, quartzo, rutilo, anatásio e zircão. $\mathrm{O}$ modelo de função de forma de pico utilizado foi pseudo-Voigt (combinação linear das funções de Cauchy e Gauss). A largura a meia altura $(\beta)$ do pico foi modelada a partir de uma função quadrática com três parâmetros refináveis, representados por U, V e W (Caglioti et al., 1958). Todos os parâmetros da célula unitária foram refinados, seletivamente. A linha de base foi modelada por uma função polinomial com quatro parâmetros. Quanto à qualidade do refinamento, foram observados os índices $R$ e a linha de diferença, os quais representam o desvio entre a difração observada e calculada.

Para as amostras de argila, a determinação da substituição do Fe por $\mathrm{Al}$ foi realizada por meio de cinco extrações sucessivas com DCB (Mehra \& Jackson, 1960). Extrações com solução de oxalato ácido de amônio e de citrato-bicarbonato (sem ditionito) foram, também, realizadas em outro grupo de amostras, enquanto os valores de $\mathrm{Fe}$ e $\mathrm{Al}$ foram utilizados para evitar possíveis contribuições graças a digestões de materiais amorfos, de aluminossilicatos cristalinos e gibbsita.

\section{Microscopia eletrônica}

As micrografias em microscopia eletrônica de transmissão foram realizadas, apenas, em amostras concentradas de óxidos de Fe dos solos amarelos. A visualização e as fotografias digitais foram realizadas em um MET JEOL JEM-200 CX, operado a 120 kv. As amostras dos horizontes do perfil $\mathrm{PA}_{1}$ foram, também, visualizadas em microscopia eletrônica de varredura em vácuo, montadas em pó sobre fita adesiva de cobre e impregnadas com ouro. As micrografias foram feitas em aparelho FEI QUANTA 200.

\section{RESULTADOS E DISCUSSÃO}

\section{Mineralogia de concentrados de óxidos de ferro}

Os espectros de difratometria de raios X(DRX) dos concentrados de óxidos de Fe dos horizontes Bt, Bw, Bhs e fragipãs são apresentados nas figuras 2 e 3 . A DRX revelou a presença de óxidos de Fe de alta cristalinidade (goethita e hematita) e de titânio (anatásio e rutilo) em todos os solos estudados. Foi identificado, também, o quartzo ( $d=0,333 \mathrm{~nm})$ em quase todas as amostras e, especificamente para os horizontes Bhs e fragipãs, foi identificado o zircão $(d=$ 0,4428 nm), cuja presença deve-se à sua alta resistência ao intemperismo.

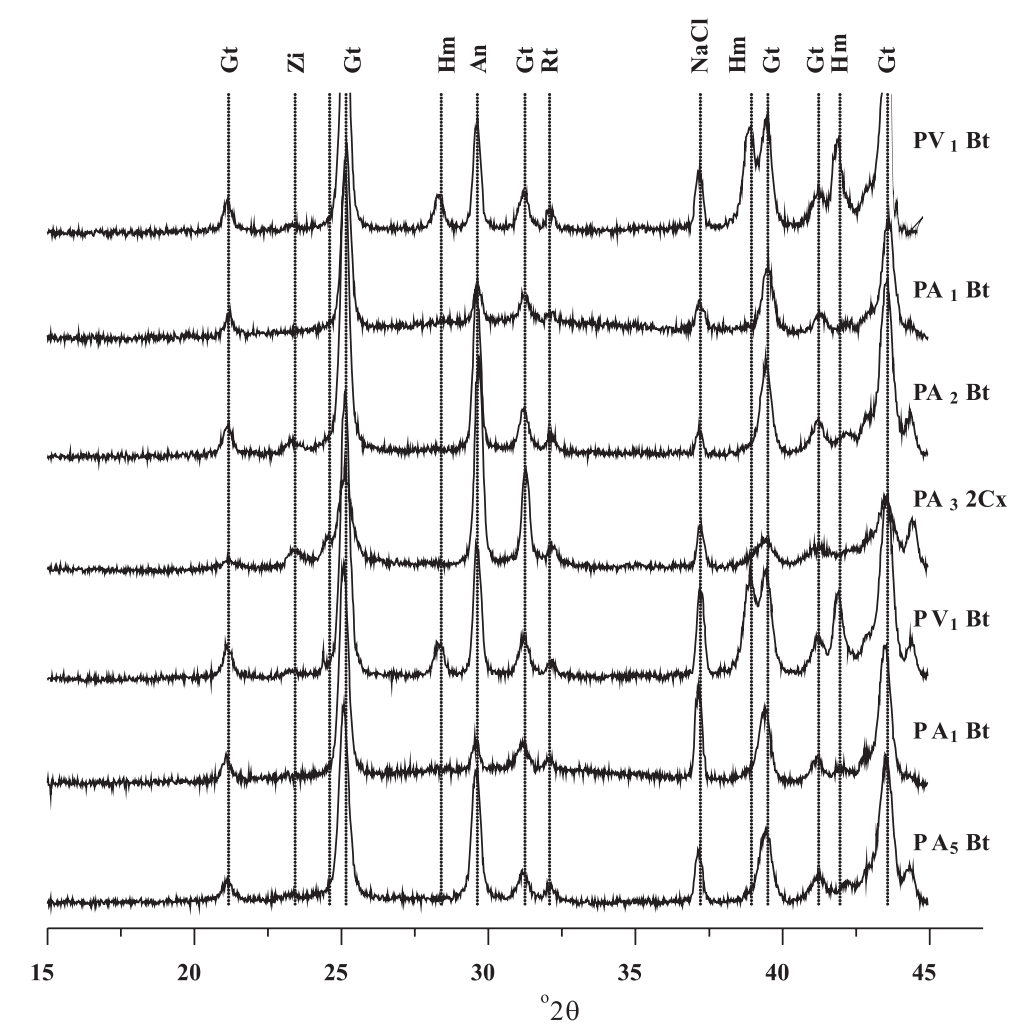

Figura 2. Difratogramas de raios $\mathrm{X}$ de concentrado de óxidos de ferro dos horizontes $\mathrm{B}$ de alguns solos estudados. Gt: goethita, Hm: hematita; An: anatásio; Rt: rutilo; Qz: quartzo; Zi: zircão; NaCl: padrão interno. 


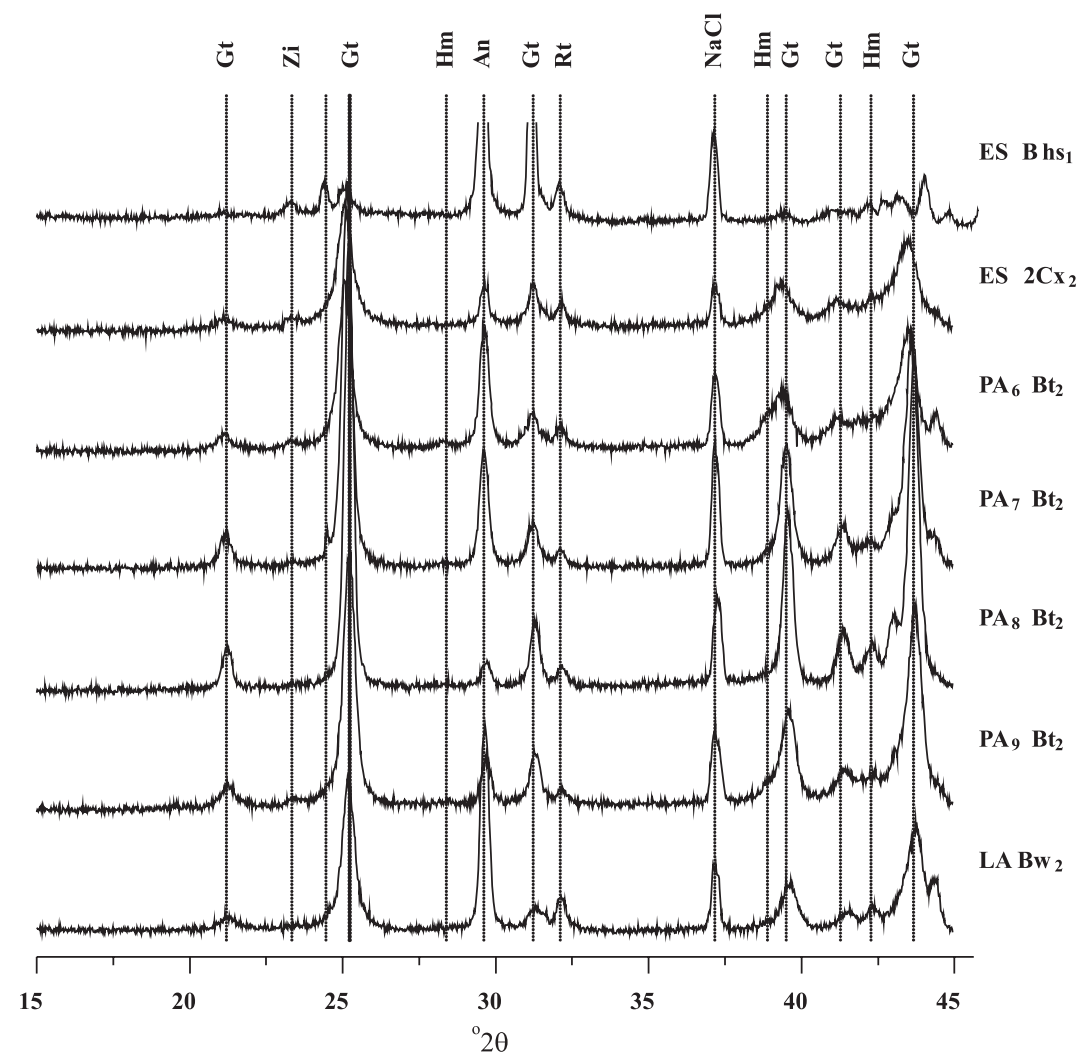

Figura 3. Difratogramas de raios $\mathrm{X}$ de concentrado de óxidos de ferro dos horizontes $\mathrm{B}$ e fragipã de alguns solos estudados. Gt: goethita, Hm: hematita; An: anatásio; Rt: rutilo; Qz: quartzo; Zi: zircão; NaCl: padrão interno.

Os teores de hematitas foram baixos, com máximo de 2,26 dag kg-1 (Quadro 2) nos solos vermelhos, confirmando seu alto poder de pigmentação (Resende, 1976; Barrón \& Torrent, 1986). Os teores de Gt variaram de 0,69 a 10,01 dag kg-1 (Quadro 2), sendo menores nos perfis derivados dos sedimentos das Formações Barreiras e Alter-do-Chão. Provavelmente, esse resultado é devido à pobreza de Fe dos sedimentos, à proximidade do lençol freático e à drenagem deficiente (presença de horizontes coesos, fragipã e duripã), que promovem maior redução do $\mathrm{Fe}$ e remoção gradativa do Fe do sistema. Os valores da relação $\mathrm{Gt} /(\mathrm{Gt}+\mathrm{Hm})$ (de 0,69 a 1,00) revelaram o domínio da goethita em todos os solos estudados, mesmo naqueles com coloração avermelhada (Quadro 2).

\section{Substituição isomórfica do $\mathrm{Fe}$ por $\mathrm{Al}$ (SI)}

Os procedimentos químicos resultaram em diferentes valores de SI para a mesma amostra. Em geral, sua determinação em concentrados de óxidos de Fe levou a valores inferiores aos obtidos pelos outros procedimentos (DRX e extração química na argila), considerando, possivelmente, a ineficiência do procedimento para esse tipo de amostra. Esse fato é mais bem compreendido, quando se observam os valores de Fe que permaneceram (residual) na amostra após as extrações com DCB $\left(\mathrm{Fe}_{\mathrm{r}}\right)$, cujos valores variaram de 4 a $31 \%$ do total extraído (Quadro 3).
Quadro 2. Proporção de goethita e hematita da fração argila, obtidas por meio dos resultados de DCB e ERD e considerando a percentagem de substituição isomórfica de ferro por alumínio nos óxidos

\begin{tabular}{|c|c|c|c|c|c|}
\hline Perfil & Classe & Horizonte & Gt & $\mathrm{Hm}$ & $(\mathrm{Gt} \stackrel{\mathrm{Gt}}{+\mathrm{Hm}})$ \\
\hline & & \multicolumn{4}{|c|}{ - dag $\mathrm{kg}^{-1}$ de argila - } \\
\hline $\mathrm{P}_{1}$ & $\mathrm{PV}_{1}$ & $\begin{array}{l}\mathrm{BA} \\
\mathrm{Bt}_{3}\end{array}$ & $\begin{array}{l}5,03 \\
5,54\end{array}$ & $\begin{array}{l}2,26 \\
2,18\end{array}$ & $\begin{array}{l}0,69 \\
0,72\end{array}$ \\
\hline $\mathrm{P}_{2}$ & $\mathrm{PA}_{1}$ & $\begin{array}{l}\mathrm{BA} \\
\mathrm{Bt}_{3}\end{array}$ & $\begin{array}{l}6,96 \\
8,88\end{array}$ & $\begin{array}{l}0,28 \\
0,48\end{array}$ & $\begin{array}{l}0,96 \\
0,95\end{array}$ \\
\hline $\mathrm{P}_{3}$ & $\mathrm{PA}_{2}$ & $\begin{array}{l}\mathrm{BA} \\
\mathrm{Bt}_{3}\end{array}$ & $\begin{array}{l}2,35 \\
3,65\end{array}$ & $\begin{array}{l}0,08 \\
0,20\end{array}$ & $\begin{array}{l}0,97 \\
0,95\end{array}$ \\
\hline $\mathrm{P}_{4}$ & $\mathrm{PA}_{3}$ & $\begin{array}{l}\mathrm{BA} \\
2 \mathrm{Cxf}_{2}\end{array}$ & $\begin{array}{l}0,69 \\
2,43\end{array}$ & $\begin{array}{l}0,00 \\
0,12\end{array}$ & $\begin{array}{l}1,00 \\
0,95\end{array}$ \\
\hline $\mathrm{P}_{5}$ & $\mathrm{PA}_{4}$ & $\begin{array}{l}\mathrm{BA} \\
\mathrm{Bt}_{2}\end{array}$ & $\begin{array}{r}7,47 \\
10,01\end{array}$ & $\begin{array}{l}0,61 \\
0,65\end{array}$ & $\begin{array}{l}0,93 \\
0,94\end{array}$ \\
\hline $\mathrm{P}_{6}$ & $\mathrm{PV}_{2}$ & $\begin{array}{l}\mathrm{BA} \\
\mathrm{Bt}_{3}\end{array}$ & $\begin{array}{l}3,33 \\
5,30\end{array}$ & $\begin{array}{l}1,47 \\
2,10\end{array}$ & $\begin{array}{l}0,69 \\
0,72\end{array}$ \\
\hline $\mathrm{P}_{7}$ & $\mathrm{ES}$ & $\begin{array}{l}\mathrm{Bhs}_{1} \\
2 \mathrm{Cx}_{2}\end{array}$ & $\begin{array}{l}0,78 \\
5,40\end{array}$ & $\begin{array}{l}0,06 \\
0,22\end{array}$ & $\begin{array}{l}0,92 \\
0,96\end{array}$ \\
\hline $\mathrm{P}_{8}$ & $\mathrm{PA}_{5}$ & $\mathrm{Bt}_{3}$ & 2,44 & 0,14 & 0,95 \\
\hline $\mathrm{P}_{9}$ & $\mathrm{PA}_{6}$ & $\mathrm{Bt}_{2}$ & 2,81 & 0,27 & 0,91 \\
\hline $\mathrm{P}_{10}$ & $\mathrm{PA}_{7}$ & $\mathrm{Bt}_{2}$ & 3,12 & 0,13 & 0,96 \\
\hline $\mathrm{P}_{11}$ & $\mathrm{PA}_{8}$ & $\mathrm{Bt}_{2}$ & 3,77 & 0,15 & 0,96 \\
\hline $\mathrm{P}_{12}$ & $\mathrm{PA}_{9}$ & $\mathrm{Bt}_{2}$ & 4,21 & 0,24 & 0,95 \\
\hline $\mathrm{P}_{13}$ & $\mathrm{LA}_{1}$ & $\mathrm{Bw}_{2}$ & 1,94 & 0,06 & 0,97 \\
\hline
\end{tabular}

Gt: goethita; Hm: hematita; Clas.: classe de solo segundo nomeclatura do SiBCS. 
Quadro 3. Substituição por alumínio determinada após extração com DCB, em concentrados de óxidos de ferro e na fração argila, e por meio do uso da equação de Schulze (1984) e Schwetmann et al. (1979); e parâmetros " $c$ " e " $a$ " da célula unitária da goethita e hematita, respectivamente

\begin{tabular}{|c|c|c|c|c|c|c|c|c|c|}
\hline \multirow[b]{2}{*}{ Perfil } & \multirow[b]{2}{*}{ Hor. } & \multicolumn{3}{|c|}{ Procedimento químico } & \multirow[b]{2}{*}{$\mathrm{Fe}_{\mathbf{r}}^{(1)}$} & \multicolumn{2}{|c|}{ Difratometria de raios $X$} & \multirow{2}{*}{$\begin{array}{c}\text { "c" } \\
\text { Gttox }\end{array}$} & \multirow{2}{*}{$\begin{array}{c}\text { "a" } \\
\mathrm{Hm}_{0}\end{array}$} \\
\hline & & $\begin{array}{c}\text { Concentração } \\
\text { de óxido }\end{array}$ & Argila $^{(2)}$ & Argila $^{(3)}$ & & Goethita $^{(4)}$ & Hematita $^{(5)}$ & & \\
\hline & & ------------ & $\mathrm{ol} \mathrm{mol}{ }^{-1}$ & ------- & $\%$ & ----- mol & $\mathrm{ol}^{-1}-{ }^{----}$ & & \\
\hline $\mathrm{PV}_{1}$ & $\begin{array}{l}\mathrm{BA} \\
\mathrm{Bt}_{3}\end{array}$ & $\begin{array}{l}0,11 \\
0,11\end{array}$ & $\begin{array}{l}0,19 \\
0,26\end{array}$ & $\begin{array}{l}0,17 \\
0,27\end{array}$ & $\begin{array}{r}7 \\
13\end{array}$ & $\begin{array}{l}0,22 \\
0,22\end{array}$ & $\begin{array}{l}0,06 \\
0,05\end{array}$ & $\begin{array}{l}2,985 \\
2,985\end{array}$ & $\begin{array}{l}5,029 \\
5,030\end{array}$ \\
\hline $\mathrm{PA}_{1}$ & $\begin{array}{l}\mathrm{BA} \\
\mathrm{Bt}_{3}\end{array}$ & $\begin{array}{l}0,16 \\
0,30\end{array}$ & $\begin{array}{l}0,29 \\
0,28\end{array}$ & $\begin{array}{l}0,29 \\
0,27\end{array}$ & $\begin{array}{l}12 \\
31\end{array}$ & $\begin{array}{l}0,23 \\
0,23\end{array}$ & $\begin{array}{l}\text { nd } \\
\text { nd }\end{array}$ & $\begin{array}{l}2,985 \\
2,984\end{array}$ & $\begin{array}{l}\text { nd } \\
\text { nd }\end{array}$ \\
\hline $\mathrm{PA}_{2}$ & $\begin{array}{l}\mathrm{BA} \\
\mathrm{Bt}_{3}\end{array}$ & $\begin{array}{l}0,20 \\
0,17\end{array}$ & $\begin{array}{l}0,35 \\
0,33\end{array}$ & $\begin{array}{l}0,32 \\
0,31\end{array}$ & $\begin{array}{l}5 \\
5\end{array}$ & $\begin{array}{l}0,22 \\
0,23\end{array}$ & $\begin{array}{l}\text { nd } \\
\text { nd }\end{array}$ & $\begin{array}{l}2,985 \\
2,985\end{array}$ & $\begin{array}{l}\text { nd } \\
\text { nd }\end{array}$ \\
\hline $\mathrm{PA}_{3}$ & $\begin{array}{l}\mathrm{BA} \\
2 \mathrm{Cxf}_{2}\end{array}$ & $\begin{array}{l}0,12 \\
0,13\end{array}$ & $\begin{array}{l}0,00 \\
0,20\end{array}$ & $\begin{array}{c}\text { nd } \\
0,36\end{array}$ & $\begin{array}{l}5 \\
8\end{array}$ & $\begin{array}{l}0,26 \\
0,24\end{array}$ & $\begin{array}{l}\text { nd } \\
\text { nd }\end{array}$ & $\begin{array}{l}2,979 \\
2,982\end{array}$ & $\begin{array}{l}\text { nd } \\
\text { nd }\end{array}$ \\
\hline $\mathrm{PA}_{4}$ & $\begin{array}{l}\mathrm{BA} \\
\mathrm{Bt}_{2}\end{array}$ & $\begin{array}{l}0,49 \\
0,26\end{array}$ & $\begin{array}{l}0,24 \\
0,25\end{array}$ & $\begin{array}{l}0,23 \\
0,24\end{array}$ & $\begin{array}{l}11 \\
22\end{array}$ & $\begin{array}{l}0,21 \\
0,21\end{array}$ & $\begin{array}{l}\text { nd } \\
\text { nd }\end{array}$ & $\begin{array}{l}2,987 \\
2,988\end{array}$ & $\begin{array}{l}\text { nd } \\
\text { nd }\end{array}$ \\
\hline $\mathrm{PV}_{2}$ & $\begin{array}{l}\mathrm{BA} \\
\mathrm{Bt}_{3}\end{array}$ & $\begin{array}{l}0,10 \\
0,11\end{array}$ & $\begin{array}{l}0,16 \\
0,18\end{array}$ & $\begin{array}{l}0,15 \\
0,17\end{array}$ & $\begin{array}{l}9 \\
8\end{array}$ & $\begin{array}{l}0,21 \\
0,22\end{array}$ & $\begin{array}{l}0,05 \\
0,02\end{array}$ & $\begin{array}{l}2,987 \\
2,986\end{array}$ & $\begin{array}{l}5,031 \\
5,034\end{array}$ \\
\hline $\mathrm{PAC}$ & $\begin{array}{l}\mathrm{Bhs}_{1} \\
2 \mathrm{Cx}_{2}\end{array}$ & $\begin{array}{l}0,09 \\
0,10\end{array}$ & $\begin{array}{l}0,00 \\
0,56\end{array}$ & $\begin{array}{c}\mathrm{nd} \\
0,57\end{array}$ & $\begin{array}{l}6 \\
8\end{array}$ & $\begin{array}{l}0,23 \\
0,20\end{array}$ & $\begin{array}{l}\text { nd } \\
\text { nd }\end{array}$ & $\begin{array}{l}2,985 \\
2,989\end{array}$ & $\begin{array}{l}\text { nd } \\
\text { nd }\end{array}$ \\
\hline $\mathrm{PA}_{5}$ & $\mathrm{Bt}_{3}$ & 0,16 & 0,32 & 0,30 & 9 & 0,24 & nd & 2,982 & nd \\
\hline $\mathrm{PA}_{6}$ & $\mathrm{Bt}_{2}$ & 0,11 & 0,19 & 0,22 & 8 & 0,22 & nd & 2,986 & nd \\
\hline $\mathrm{PA}_{7}$ & $\mathrm{Bt}_{2}$ & 0,20 & 0,31 & 0,32 & 15 & 0,26 & nd & 2,979 & nd \\
\hline $\mathrm{PA}_{8}$ & $\mathrm{Bt}_{2}$ & 0,16 & 0,32 & 0,32 & 13 & 0,25 & nd & 2,981 & nd \\
\hline $\mathrm{PA}_{9}$ & $\mathrm{Bt}_{2}$ & 0,15 & 0,32 & 0,34 & 9 & 0,28 & nd & 2,975 & nd \\
\hline $\mathrm{LA}_{1}$ & $\mathrm{Bw}_{2}$ & 0,16 & 0,42 & 0,41 & 13 & 0,33 & nd & 2,967 & nd \\
\hline
\end{tabular}

(1) Percentagem de ferro que permaneceu nos concentrados após o ataque de DCB. ${ }^{(2)}$ Eliminando o ferro e alumínio extraídos por citrato-bicarbonato. ${ }^{(3)}$ Eliminando o ferro e alumínio extraídos por oxalato. ${ }^{(4)}$ De Schulze (1984): mol \% $\mathrm{Al}=1.730-572$ c. ${ }^{(5)} \mathrm{De}$ Schwertmann et al, (1979): $\mathrm{mol} \% \mathrm{Al}=647(5,0376$-a). nd: não detectado.

Dessa forma, para melhor estimativa da SI, optouse por extração na fração argila. Para os Argissolos, os valores variaram de 0,15 a $0,41 \mathrm{~mol} \mathrm{~mol}^{-1}$, com média de $0,27 \mathrm{~mol} \mathrm{~mol}^{-1}$ (Quadro 3), sendo maiores para os solos de coloração amarelada, indicando a presença de goethita com alta SI. Esses resultados estão de acordo com aqueles encontrados por outros autores, em solos brasileiros, determinados diretamente (procedimentos químicos) ou indiretamente (uso da DRX) (Fontes \& Weed, 1991; Ker, 1995; Melo et al., 2001).

Em geral, os altos valores de SI revelam um ambiente de acentuada intemperização, não hidromórfico (exceto os Espodossolos) e sob condições de baixo $\mathrm{pH}$ (alta atividade de $\mathrm{Al}$ ) (Fitzpatrick \& Schwertmann, 1982), coerente com as atuais condições ambientais das diferentes regiões de coleta dos perfis. A SI de $\sim 0,41 \mathrm{~mol} \mathrm{~mol}^{-1}$ do perfil de Latossolo foi superior a $0,33 \mathrm{~mol} \mathrm{~mol}^{-1}$ (provável limite máximo tolerado pela estrutura da goethita) (Thiel, 1963; Schwertmann \& Taylor, 1989), refletindo a possibilidade de solubilização de outras fontes de $\mathrm{Al}$ com o DCB e insolúveis em citrato-bicarbonato e oxalato, como, por exemplo, gibbsita, confirmada por DRX em amostras de argila desferrificadas (dados não apresentados). Contudo, valores superiores a este limite têm sido mencionados na literatura. Brenevoi \& Furmakova (1975), citados por Fey \& Dixon (1981), reportaram valores de $0,47 \mathrm{~mol} \mathrm{~mol}^{-1}$ para goethitas sintetizadas a partir de soluções sulfatadas. Fey \& Le Roux (1977) encontraram, em alguns Oxissolos, valores de $0,46 \mathrm{~mol} \mathrm{~mol}^{-1}$ após correção com o Al removido por solução de oxalato de amônio. Tal fato mostra que as propriedades cristaloquímicas dos óxidos sintetizados não condizem com materiais pedogenéticos, possivelmente, em virtude da grande diversidade de ambientes no solo.

Os valores de SI, determinados por DRX ( $\mathrm{SI}_{\mathrm{DRX}}$ ), foram maiores para as goethitas do que para as hematitas (Quadro 3), coerentes com resultados disponíveis na literatura no Brasil (Fontes \& Weed, 1991; Melo et al., 2001). Considerando os solos goethíticos, foram observados menores valores de $\mathrm{SI}_{\mathrm{DRX}}$ em relação àqueles determinados pelos procedimentos químicos na argila, revelando que a aplicação de equação de Schulze (1984) em amostras naturais deve 
ser cautelosamente realizada. Schwertmann \& Carlson (1994), ressaltando a necessidade de demonstrar a existência de relações entre as goethitas naturais e as obtidas em laboratório, propuseram uma nova equação, obtida por ajuste do parâmetro $c$ com a SI de 75 amostras naturais. A aplicação desta equação (dado não apresentado) também gerou resultados inferiores aos obtidos no presente trabalho. Dessa forma, tornam-se necessários novos estudos, buscando o entendimento entre o tamanho da célula unitária (parâmetros $a, b$ e c) e a substituição isomórfica por Al em ambientes naturais.

Os valores da substituição isomórfica de Fe por $\mathrm{Al}$, determinados quimicamente na fração argila (Quadro 3), apresentaram significativa relação com as dimensões $a, b$ e $c$ da célula unitária da goethita. Concordando com os resultados de Schulze (1984) e Schwertmann \& Carlson (1994), os melhores ajustes foram encontrados para as dimensões " $b$ " e " $c$ ". De acordo com Fey \& Dixon (1981) e Schulze (1984), o pior ajuste para "a" pode ser decorrente de possíveis imperfeições nesse eixo cristalográfico (visualizado pelo maior afastamento da linha de Vegard), promovidas por um grupo $\mathrm{OH}$ adicional na estrutura da goethita.

Schulze (1984) e Schwertmann \& Carlson (1994) descrevem a dimensão "c" como a mais sensível para a estimativa da substituição isomórfica de $\mathrm{Fe}$ por $\mathrm{Al}$ em goethitas, o que foi confirmado nos resultados do presente trabalho. Por outro lado, graças seu excelente ajuste (Figura 4), a dimensão "b" também pode ser utilizada para este fim. Schwertmann \& Carlson (1994) já relataram essa possibilidade de uso, caso mais picos fossem utilizados em sua determinação. Assim, é provável que o ajuste obtido seja conseqüência do uso de todo o espectro de DRX (na faixa de 15 a $80^{\circ} 2 \theta$ ) na estimativa das dimensões da célula unitária, por meio do ajuste Rietveld (Rietveld, 1969).

Os valores de declividade das curvas das dimensões "a", "b" e "c" diferem daqueles obtidos segundo a lei de Vegard (Quadro 4). Esse resultado indica uma di-
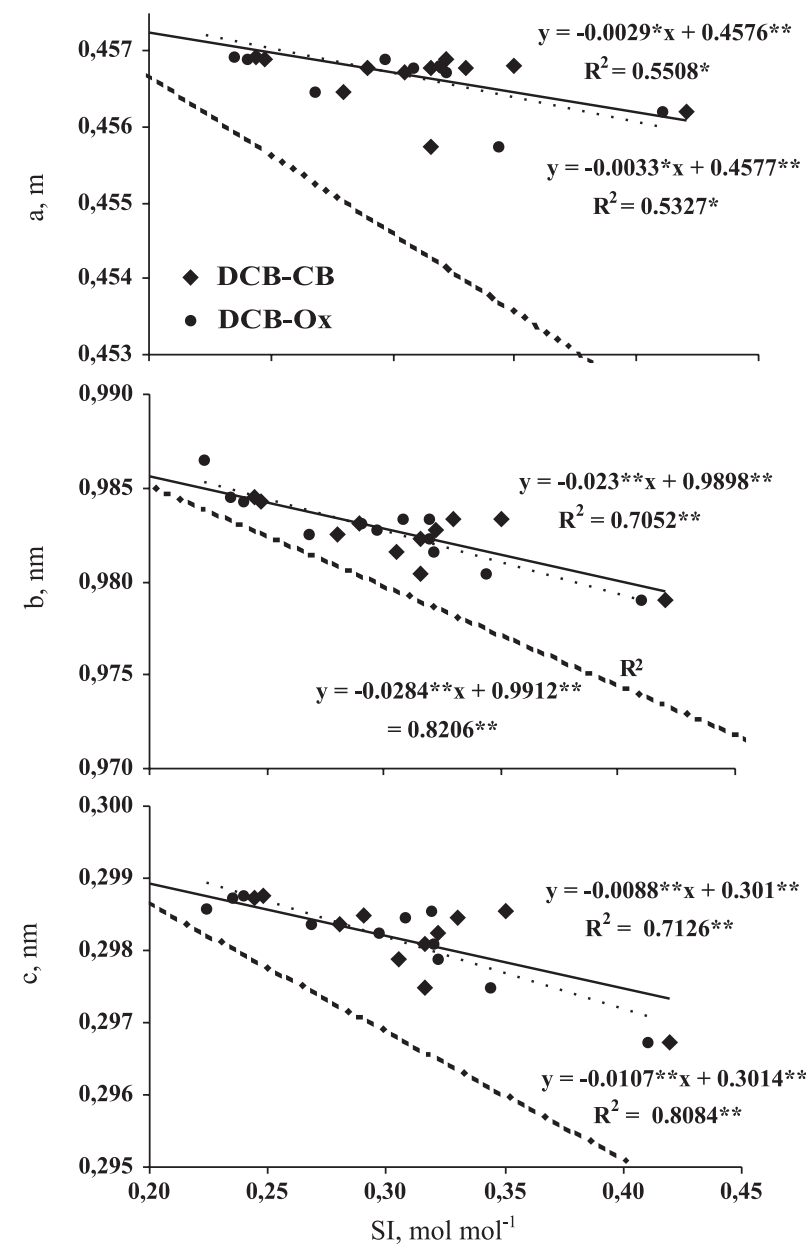

Figura 4. Dimensões da célula unitária da goethita de acordo com a substituição isomórfica de ferro por alumínio, para amostras de solos com coloração amarelada.

minuição da célula unitária pela incorporação de Al, porém em menor magnitude do que aquele obtido por Schwertmann \& Carlson (1994) para solos tropicais,

Quadro 4. Relações lineares entre os parâmetros da célula unitária e substituição de ferro por alumínio alumínio de goethitas de solo e sintética

\begin{tabular}{|c|c|c|c|c|c|c|}
\hline Grupo de amostra & $\mathbf{n}$ & $\begin{array}{l}\text { Amplitude } \\
\text { de Al subst. }\end{array}$ & Var. & Interc. & $\begin{array}{l}\text { decliv. } \\
\left(x 10^{2}\right)\end{array}$ & $\mathbf{R}^{2}$ \\
\hline & & $\mathrm{mol} \mathrm{mol}^{-1}$ & & $\mathrm{~nm}$ & & \\
\hline Acúmulos de óxidos de $\mathrm{Fe}$ em solos arenosos $\left(\right.$ Espanha) ${ }^{(1)}$ & 7 & $0,14-0,29$ & $\mathrm{~d}_{111}$ & 0,2442 & $-0,57$ & $-0,82$ \\
\hline \multirow[t]{3}{*}{ Minério, Finlândia ${ }^{(2)}$} & 30 & $0,02-0,19$ & a & 0,4617 & $-1,10$ & $-0,90$ \\
\hline & & & $\mathrm{b}$ & 0,9969 & $-3,30$ & $-0,94$ \\
\hline & & & $\mathrm{c}$ & 0,3020 & $-0,90$ & $-0,95$ \\
\hline $\begin{array}{l}\text { Solos Tropicais } \\
\text { (a) África do Sul, Nigéria, Brasil, Índia e }\end{array}$ & 84 & $0,01-0,32$ & a & 0,4610 & $-1,10$ & $-0,68$ \\
\hline \multirow[t]{2}{*}{ Nova Caledônia ${ }^{(2)}$} & & & $\mathrm{b}$ & 0,9970 & $-5,90$ & $-0,94$ \\
\hline & & & $\mathrm{c}$ & 0,3026 & $-2,07$ & $-0,98$ \\
\hline \multirow[t]{3}{*}{ (b) Brasil (o presente trabalho) } & 12 & & a & 0,4577 & $-0,33$ & $-0,53$ \\
\hline & & & $\mathrm{b}$ & 0,9912 & $-2,84$ & $-0,82$ \\
\hline & & & $\mathrm{c}$ & 0,3014 & $-1,07$ & $-0,71$ \\
\hline Lei de Vegard & - & $0-100$ & $\mathrm{c}$ & 0,3022 & $-1,76$ & $-1,00$ \\
\hline
\end{tabular}

(1) Barral Silva \& Rivera (1987). ${ }^{(2)}$ Schwertmann \& Carlson (1994). 
enquanto os interceptos apresentaram-se semelhantes (Figura 5). Dessa forma, as goethitas dos solos dos Tabuleiros Costeiros e Interioranos parecem ter sido formadas em um ambiente peculiar. Em concordância, foram observados baixos valores de largura a meia altura (LMC) dos picos, em relação aos espera-

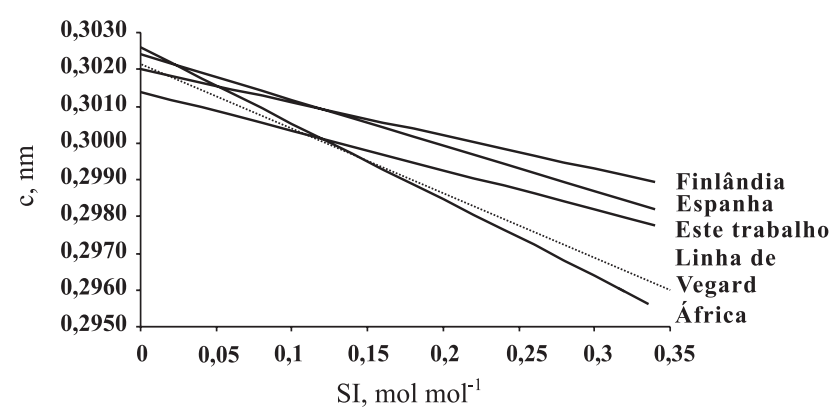

Figura 5. Comparação entre os valores do parâmetro "c" da célula unitária e substituição isomórfica de ferro por alumínio de goethita de doze amostras de solos de cor amarelada (ausência de hematita confirmada por DRX). A linha pontilhada representa a lei de Vegard, linha contínua e mais grossa, representa os resultados do presente trabalho. dos para goethita com semelhante conteúdo de SI. Para $\mathrm{LMC}_{110}$, obteve-se o valor médio de 0,246 $0,089^{\circ} 2 \theta$, inferior àquele obtido por Schwertmann \& Carlson (1994), de 0,50 $\pm 0,15^{\circ} 2 \theta$, evidenciando a presença de partículas de dimensões superiores à obtidas pelos mesmos autores, para a mesma SI.

\section{Extração com DCB e oxalato ácido de amônio}

Os teores de Fe extraídos por meio do tratamento de DCB ( $\left.\mathrm{Fe}_{\mathrm{DCB}}\right)$ variaram de 0,61 a 8,01 dag kg-1 de argila (Quadro 5). Os menores teores foram observados nos solos localizados nas áreas planas, às vezes depressionais, dos Tabuleiros, cujo material de origem são os sedimentos da Formação Barreiras (perfis $\mathrm{PAC}, \mathrm{PA}_{2}, \mathrm{PA}_{3}, \mathrm{PA}_{5}, \mathrm{PA}_{6}, \mathrm{PA}_{7}, \mathrm{PA}_{8}$ e $\mathrm{PA}$ ) ou sedimentos correlatos (perfil LA $\mathrm{L}_{1}$; Formação Alter do Chão). Desses, o Espodossolo (ES), provavelmente em razão de sua drenagem deficiente e translocação dos colóides (favorecida pela textura arenosa), apresentou valor ainda mais baixo, de $0,76 \mathrm{dag} \mathrm{kg}^{-1}$ para 0 horizonte eluvial. Para aqueles perfis localizados em topo e terço superior de encosta de relevo suaveondulado $\left(\mathrm{PA}_{1}, \mathrm{PA}_{4}, \mathrm{PV}_{1}\right.$ e $\left.\mathrm{PV}_{2}\right)$, os teores de $\mathrm{Fe}_{\mathrm{DCB}}$ mostraram-se mais elevados, variando de 4 a 8 dag $\mathrm{kg}^{-1}$,

Quadro 5. Teores de ferro e alumínio obtidos em seis extrações sucessivas com ditionito-citrato-bicarbonato $\left(\mathrm{Fe}_{\mathrm{DCB}}\right.$ e $\left.\mathrm{Al}_{\mathrm{DCB}}\right)$, em seis extrações sucessivas de citrato-bicarbonato $\left(\mathrm{Fe}_{\mathrm{CB}} \mathrm{e} \mathrm{Al}_{\mathrm{CB}}\right)$, uma extração com oxalato de amônio $\left(\mathrm{Fe}_{\mathrm{OX}} \mathrm{e} \mathrm{Al}_{\mathrm{OX}}\right)$, e algumas relações entre elas

\begin{tabular}{|c|c|c|c|c|c|c|c|c|c|c|c|c|c|c|c|c|c|}
\hline \multirow{2}{*}{ Perfil } & \multirow{2}{*}{ Clas. } & \multirow{2}{*}{ Hor. } & \multicolumn{3}{|c|}{ Extração } & \multirow{2}{*}{$\Sigma$} & \multicolumn{3}{|c|}{ Extração } & \multirow{2}{*}{$\sum^{(1)}$} & \multirow{2}{*}{$\mathbf{F e}_{\mathrm{CB}}$} & \multirow{2}{*}{$\mathrm{Al}_{\mathrm{CB}}$} & \multirow{2}{*}{ Feox } & \multirow{2}{*}{ Alox } & \multirow{2}{*}{$\frac{\text { Feox }}{\text { FedcB }}$} & \multirow{2}{*}{$\frac{\mathrm{Alox}}{\mathrm{Al}_{\mathrm{DCB}}}$} & \multirow{2}{*}{$\frac{\text { Alox }}{\text { Feox }}$} \\
\hline & & & $1^{a}$ & $2^{a}$ & $3^{a}-6^{a}$ & & $1^{a}$ & $2^{a}$ & $3^{a}-6^{a}$ & & & & & & & & \\
\hline & & & \multicolumn{4}{|c|}{$-\mathrm{Fe}_{\mathrm{DCB}}$, dag $\mathrm{kg}^{-1}-$} & \multicolumn{3}{|c|}{$-\mathrm{Al}_{\mathrm{DCB}}$, dag kg${ }^{-1}-$} & & \multicolumn{4}{|c|}{ dag $\mathrm{kg}^{-1}$} & & & \\
\hline $\mathrm{P}_{1}$ & $\mathrm{PV}_{1}$ & $\begin{array}{l}\mathrm{BA} \\
\mathrm{Bt}_{3}\end{array}$ & $\begin{array}{l}3,22 \\
2,85\end{array}$ & $\begin{array}{l}1,24 \\
1,12\end{array}$ & $\begin{array}{l}1,51 \\
2,31\end{array}$ & $\begin{array}{l}5,97 \\
6,28\end{array}$ & $\begin{array}{l}0,24 \\
0,36\end{array}$ & $\begin{array}{l}0,20 \\
0,24\end{array}$ & $\begin{array}{l}0,38 \\
0,69\end{array}$ & $\begin{array}{l}0,82 \\
1,29\end{array}$ & $\begin{array}{l}0,07 \\
0,06\end{array}$ & $\begin{array}{l}0,15 \\
0,24\end{array}$ & $\begin{array}{l}0,14 \\
0,07\end{array}$ & $\begin{array}{l}0,25 \\
0,21\end{array}$ & $\begin{array}{l}0,02 \\
0,01\end{array}$ & $\begin{array}{l}0,31 \\
0,16\end{array}$ & $\begin{array}{l}1,81 \\
3,00\end{array}$ \\
\hline $\mathrm{P}_{2}$ & $\mathrm{PA}_{1}$ & $\begin{array}{l}\mathrm{BA} \\
\mathrm{Bt}_{3}\end{array}$ & $\begin{array}{l}1,68 \\
2,01\end{array}$ & $\begin{array}{l}1,24 \\
1,59\end{array}$ & $\begin{array}{l}2,27 \\
3,20\end{array}$ & $\begin{array}{l}5,19 \\
6,80\end{array}$ & $\begin{array}{l}0,34 \\
0,41\end{array}$ & $\begin{array}{l}0,24 \\
0,28\end{array}$ & $\begin{array}{l}0,53 \\
0,72\end{array}$ & $\begin{array}{l}1,10 \\
1,41\end{array}$ & $\begin{array}{l}0,08 \\
0,05\end{array}$ & $\begin{array}{l}0,10 \\
0,16\end{array}$ & $\begin{array}{l}0,13 \\
0,05\end{array}$ & $\begin{array}{l}0,11 \\
0,22\end{array}$ & $\begin{array}{l}0,03 \\
0,01\end{array}$ & $\begin{array}{l}0,10 \\
0,15\end{array}$ & $\begin{array}{l}0,83 \\
4,69\end{array}$ \\
\hline $\mathrm{P}_{3}$ & $\mathrm{PA}_{2}$ & $\begin{array}{l}\mathrm{BA} \\
\mathrm{Bt}_{3}\end{array}$ & $\begin{array}{l}0,91 \\
1,17\end{array}$ & $\begin{array}{l}0,48 \\
0,61\end{array}$ & $\begin{array}{l}0,24 \\
0,89\end{array}$ & $\begin{array}{l}1,63 \\
2,67\end{array}$ & $\begin{array}{l}0,23 \\
0,32\end{array}$ & $\begin{array}{l}0,14 \\
0,19\end{array}$ & $\begin{array}{l}0,12 \\
0,26\end{array}$ & $\begin{array}{l}0,49 \\
0,77\end{array}$ & $\begin{array}{l}0,08 \\
0,05\end{array}$ & $\begin{array}{l}0,08 \\
0,15\end{array}$ & $\begin{array}{l}0,08 \\
0,06\end{array}$ & $\begin{array}{l}0,14 \\
0,20\end{array}$ & $\begin{array}{l}0,05 \\
0,02\end{array}$ & $\begin{array}{l}0,28 \\
0,27\end{array}$ & $\begin{array}{l}1,63 \\
3,50\end{array}$ \\
\hline $\mathrm{P}_{4}$ & $\mathrm{PA}_{3}$ & $\begin{array}{l}\mathrm{BA} \\
2 \mathrm{Cxf}_{2}\end{array}$ & $\begin{array}{l}0,35 \\
1,72\end{array}$ & $\begin{array}{l}0,22 \\
0,19\end{array}$ & $\begin{array}{l}0,05 \\
0,08\end{array}$ & $\begin{array}{l}0,62 \\
1,98\end{array}$ & $\begin{array}{l}0,61 \\
0,80\end{array}$ & $\begin{array}{l}0,11 \\
0,07\end{array}$ & $\begin{array}{l}0,11 \\
0,05\end{array}$ & $\begin{array}{l}0,83 \\
0,92\end{array}$ & $\begin{array}{l}0,19 \\
0,57\end{array}$ & $\begin{array}{l}0,95 \\
0,75\end{array}$ & $\begin{array}{c}\text { nd } \\
0,84\end{array}$ & $\begin{array}{c}\text { nd } \\
0,61\end{array}$ & $\begin{array}{c}\text { nd } \\
0,74\end{array}$ & $\begin{array}{c}\text { nd } \\
0,66\end{array}$ & $\begin{array}{c}\text { nd } \\
0,73\end{array}$ \\
\hline $\mathrm{P}_{5}$ & $\mathrm{PA}_{4}$ & $\begin{array}{l}\mathrm{BA} \\
\mathrm{Bt}_{2}\end{array}$ & $\begin{array}{l}2,34 \\
2,57\end{array}$ & $\begin{array}{l}1,40 \\
1,23\end{array}$ & $\begin{array}{l}2,38 \\
4,21\end{array}$ & $\begin{array}{l}6,12 \\
8,01\end{array}$ & $\begin{array}{l}0,36 \\
0,40\end{array}$ & $\begin{array}{l}0,19 \\
0,15\end{array}$ & $\begin{array}{l}0,43 \\
0,76\end{array}$ & $\begin{array}{l}0,98 \\
1,31\end{array}$ & $\begin{array}{l}0,06 \\
0,06\end{array}$ & $\begin{array}{l}0,04 \\
0,04\end{array}$ & $\begin{array}{l}0,07 \\
0,04\end{array}$ & $\begin{array}{l}0,09 \\
0,12\end{array}$ & $\begin{array}{c}0,01 \\
0,004\end{array}$ & $\begin{array}{l}0,09 \\
0,09\end{array}$ & $\begin{array}{l}1,21 \\
3,31\end{array}$ \\
\hline $\mathrm{P}_{6}$ & $\mathrm{PV}_{2}$ & $\begin{array}{l}\mathrm{BA} \\
\mathrm{Bt}_{3}\end{array}$ & $\begin{array}{l}2,93 \\
3,19\end{array}$ & $\begin{array}{l}0,69 \\
1,21\end{array}$ & $\begin{array}{l}0,45 \\
1,79\end{array}$ & $\begin{array}{l}4,07 \\
6,19\end{array}$ & $\begin{array}{l}0,22 \\
0,18\end{array}$ & $\begin{array}{l}0,10 \\
0,17\end{array}$ & $\begin{array}{l}0,10 \\
0,33\end{array}$ & $\begin{array}{l}0,43 \\
0,68\end{array}$ & $\begin{array}{l}0,04 \\
0,05\end{array}$ & $\begin{array}{l}0,05 \\
0,04\end{array}$ & $\begin{array}{l}0,06 \\
0,05\end{array}$ & $\begin{array}{l}0,10 \\
0,09\end{array}$ & $\begin{array}{l}0,02 \\
0,01\end{array}$ & $\begin{array}{l}0,23 \\
0,13\end{array}$ & $\begin{array}{l}1,59 \\
1,71\end{array}$ \\
\hline $\mathrm{P}_{7}$ & $\mathrm{ES}$ & $\begin{array}{l}\mathrm{Bhs}_{1} \\
2 \mathrm{Cx}_{2}\end{array}$ & $\begin{array}{l}0,61 \\
2,35\end{array}$ & $\begin{array}{l}0,10 \\
0,30\end{array}$ & $\begin{array}{l}0,05 \\
0,16\end{array}$ & $\begin{array}{l}0,76 \\
2,81\end{array}$ & $\begin{array}{l}4,39 \\
2,12\end{array}$ & $\begin{array}{l}0,27 \\
0,12\end{array}$ & $\begin{array}{l}0,25 \\
0,21\end{array}$ & $\begin{array}{l}4,91 \\
2,45\end{array}$ & $\begin{array}{l}0,84 \\
0,70\end{array}$ & $\begin{array}{l}5,40 \\
1,13\end{array}$ & $\begin{array}{c}\text { nd } \\
1,15\end{array}$ & $\begin{array}{c}\text { nd } \\
1,38\end{array}$ & $\begin{array}{c}\text { nd } \\
0,69\end{array}$ & $\begin{array}{c}\text { nd } \\
0,56\end{array}$ & $\begin{array}{c}\text { nd } \\
1,20\end{array}$ \\
\hline $\mathrm{P}_{8}$ & $\mathrm{PA}_{5}$ & $\mathrm{Bt}_{3}$ & 0,94 & 0,32 & 0,53 & 1,79 & 0,31 & 0,09 & 0,18 & 0,58 & 0,03 & 0,17 & 0,04 & 0,22 & 0,03 & 0,39 & 5,12 \\
\hline $\mathrm{P}_{9}$ & $\mathrm{PA}_{6}$ & $\mathrm{Bt}_{2}$ & 1,98 & 0,30 & 0,16 & 2,44 & 0,36 & 0,07 & 0,07 & 0,50 & 0,09 & 0,24 & 0,16 & 0,19 & 0,07 & 0,37 & 1,18 \\
\hline $\mathrm{P}_{10}$ & $\mathrm{PA}_{7}$ & $\mathrm{Bt}_{2}$ & 1,07 & 0,33 & 0,90 & 2,29 & 0,34 & 0,13 & 0,21 & 0,68 & 0,05 & 0,21 & 0,06 & 0,18 & 0,03 & 0,26 & 2,78 \\
\hline $\mathrm{P}_{11}$ & $\mathrm{PA}_{8}$ & $\mathrm{Bt}_{2}$ & 1,17 & 0,42 & 1,13 & 2,73 & 0,34 & 0,15 & 0,26 & 0,76 & 0,06 & 0,16 & 0,06 & 0,15 & 0,02 & 0,20 & 2,45 \\
\hline $\mathrm{P}_{12}$ & $\mathrm{PA}_{9}$ & $\mathrm{Bt}_{2}$ & 2,33 & 0,21 & 0,58 & 3,12 & 0,60 & 0,14 & 0,21 & 0,95 & 0,08 & 0,27 & 0,11 & 0,19 & 0,04 & 0,20 & 1,68 \\
\hline $\mathrm{P}_{13}$ & $\mathrm{LA}_{1}$ & $\mathrm{Bw}_{2}$ & 0,64 & 0,22 & 0,37 & 1,23 & 0,34 & 0,06 & 0,16 & 0,56 & 0,11 & 0,13 & 0,16 & 0,20 & 0,15 & 0,36 & 1,21 \\
\hline
\end{tabular}

(1) Soma das seis 6 extrações com DCB na fração argila. nd: não determinado. 
sendo derivados de materiais do Pré-Cambriano, com possível mistura com os sedimentos da Formação Barreiras.

Com exceção dos Espodossolos e fragipã do $\mathrm{PA}_{3}$, apenas $50 \%$ do total de $\mathrm{Fe}_{\mathrm{DCB}}$ foi removido na primeira extração, indicando alta resistência à redução dos óxidos de Fe, mostrando-se maior para as amostras amareladas. De acordo com Torrent et al. (1987) e Fontes (1988), a maior substituição de Fe por Al nas goethitas do que nas hematitas é a principal razão da alta resistência à extração de Fe por processos redutivos. Corroborando os resultados desses autores, foi verificada correlação negativa e muito significativa entre os valores de substituição isomórfica e $\mathrm{Fe}_{\mathrm{DCB}}$ da primeira extração $\left(r=-0,85^{0,1 \%}\right)$.

Para os horizontes fragipãs do $\mathrm{ES}$ e $\mathrm{PA}_{3}$, embora amarelados, cerca de $85 \%$ do $\mathrm{Fe}_{\mathrm{DCB}}$ foi removido na primeira extração, evidenciando que a goethita desses horizontes não deve apresentar alta substituição por $\mathrm{Al}$, não concordando com a SI determinada de 0,56 e 0,36 $\mathrm{mol} \mathrm{mol}^{-1}$, respectivamente (Quadro 3). Essa discrepância deve-se, possivelmente, à superestimativa da SI em razão da presença de compostos de $\mathrm{Al}$ de baixa cristalinidade, comuns nos fragipãs no Brasil e no mundo (Boulet et al., 1998), revelando a participação desses compostos em sua cimentação.

Os teores de Fe extraído por oxalato de amônio $\left(\mathrm{Fe}_{\mathrm{OX}}\right)$ mostraram-se maiores nos fragipãs. Aliados aos valores da relação $\mathrm{Fe}_{\mathrm{OX}} / \mathrm{Fe}_{\mathrm{DCB}}$, esses resultados indicam maior participação relativa das formas de $\mathrm{Fe}$ menos cristalinas. Para os Argissolos, foram obtidas menores relações (menores que 0,05), indicando a participação das formas cristalinas (hematitas e goethitas, confirmadas pelos espectros de DRX) em sua constituição. A relação de 0,15 para o solo LA depende, possivelmente, de maiores processos redutivos do $\mathrm{Fe}$ conferidos pelo ambiente úmido, em que se encontra este solo (Amazonas). Resultados semelhantes foram obtidos por Moreau (2001), Melo et al. (2001) e Ker (1995) para Latossolos, Argissolos e Espodossolos do Brasil.

$\mathrm{O} \mathrm{Fe}_{\mathrm{Ox}}$ apresentou correlação significativa $(\mathrm{r}=$ 0,990,1\%) com os teores de Fe extraídos por citratobicarbonato $\left(\mathrm{Fe}_{\mathrm{CB}}\right)$, revelando que estes extratores removem formas semelhantes de Fe (Fernandes, 2000). Correlação semelhante também foi encontrada entre o $\mathrm{Al}_{\mathrm{OX}}$ e o $\mathrm{Al}_{\mathrm{CB}}\left(\mathrm{r}=0,96^{0,1 \%}\right)$.

Os valores de $\mathrm{Al}_{\mathrm{DCB}}$ variaram de acordo com a classe de solo. Os maiores valores foram observados, para os horizontes espódicos (Bhs) e fragipã do Espodossolo, e os menores para os Argissolos e o Latossolo (Quadro 5). Subtraindo os valores de $\mathrm{Al}_{\mathrm{DCB}}$ de $\mathrm{Al}_{\mathrm{CB}}$, observa-se que os primeiros são compostos predominantemente por formas amorfas e, ou complexos organo-Al. Em média, $84 \%$ do total de $\mathrm{Al}$ foi removido na primeira extração nos Espodossolos, valor este bem superior ao dos Argissolos (43\%). Para os Argissolos e Latossolos, o $\mathrm{Al}_{\mathrm{DCB}}$ foi continuamente liberado por extrações sucessivas, sugerindo dissoluções de minerais aluminossilicatados, provavelmente, caulinitas de menor tamanho e menor cristalinidade (Fontes \& Weed, 1991), e a presença de óxidos de $\mathrm{Fe}$ com $\mathrm{Al}$ estrutural altamente resistentes.

\section{Propriedades cristalográficas da goethita}

Em geral, os modelos matemáticos geraram valores distintos de DMC para o eixo cristalográfico "a" e "b" (DMC e DMC $_{\mathrm{b}}$ ) (Quadro 6). Para a maioria das amostras, o $\mathrm{DMC}_{\mathrm{a}}$ determinado de acordo com Henke et al. (1978) foi superior ao obtido segundo Keijser et al. (1983). Para o $\mathrm{DMC}_{\mathrm{b}}$ não foi observada essa tendência, sendo seus valores equivalentes. A relação entre $\mathrm{DMC}_{\mathrm{a}}$ e $\mathrm{DMC}_{\mathrm{b}}$ próxima de 1 indica um crescimento similar, ao longo dos eixos cristalográficos. Os valores de 1,6 são ainda bem inferiores aos valores esperados para uma morfologia aciculada, sendo a forma aproximadamente esférica a mais comum nas goethitas de solo (Schwertmann, 1988). Essa forma isodimensional foi, também, identificada por Fontes \& Weed (1991) para as goethitas de Latossolos da região do Triângulo Mineiro.

As micrografias de microscopia eletrônica de transmissão (MET) e de varredura (MEV) confirmaram essa forma isodimensional para as goethitas dos solos estudados, que apresentaram bordas serrilhadas, possivelmente, em razão do prétratamento com NaOH $5 \mathrm{~mol} \mathrm{~L}^{-1}$ (Figura 6). Nas micrografias, identificaram-se aglomerados de composição indefinida, de forma esférica e DMC médio de 10 nm (Figura 6). De acordo com os resultados de Kämpf \& Schwertmann (1982) e por não se observar em picos nos espectros de DRX, é possível que estes materiais sejam resíduos amorfos de composição silicatada ou aluminossilicatada da dissolução da caulinita.

A estimativa da superfície específica (SE) (Quadro 6), segundo Henke et al. (1978) e Keijser et al. (1983), apresenta pequena variação, com média geral de $23 \mathrm{~m}^{2} \mathrm{~g}^{-1}$. Os resultados obtidos de acordo com Henke et al. (1978) apresentaram correlação significativa com o $\mathrm{DMC}_{\mathrm{a}}\left(\mathrm{r}=-0,96^{0,1 \%}\right), \mathrm{DMC}_{\mathrm{b}}\left(\mathrm{r}=-0,91^{0,1 \%}\right)$ e com $\sqrt{ }<\mathrm{e}^{2}>\left(\mathrm{r}=-0,61^{0,1} \%\right)$ do plano (110), evidenciando a contribuição do tamanho da partícula e das imperfeições cristalográficas nos valores da superfície específica. As maiores SE e menores DMC e $\sqrt{ }<\mathrm{e}^{2}>$ foram observadas nos materiais dos fragipãs, confirmando que outros fatores, além do material de origem, sobretudo as condições biopedoclimáticas, são importantes para definir a natureza e as características dos óxidos de Fe no solo.

Os valores de largura a meia altura (LMA) para os picos (110), (111) e (130) da goethita variaram de 0,163 a 0,$462 ; 0,257$ a 0,702 ; e 0,2193 a 0,7426 (todos em ${ }^{\circ} 2 \theta$ ), respectivamente, sugerindo variação no tamanho e, ou grau de cristalinidade das goethitas dos solos estudados. De acordo com Fitzpatrick \& 
Quadro 6. Diâmetro médio do cristalito (DMC), microtensões $\left(\sqrt{ }<\mathrm{e}^{2}>\right)$, superfície específica (SE) e relação $\mathrm{DMC}_{\mathrm{a}} / \mathrm{DMC}_{\mathrm{b}}$ da goethita determinados por dois modelos matemáticos

\begin{tabular}{|c|c|c|c|c|c|c|c|c|c|c|c|}
\hline \multirow{3}{*}{ Perfil } & \multirow{3}{*}{ Hor. } & \multicolumn{4}{|c|}{ Tamanho médio dos cristalinos da goethita } & \multirow{2}{*}{\multicolumn{2}{|c|}{$\begin{array}{l}\text { Keijser } \\
\sqrt{ }<\mathbf{e}^{2}>\end{array}$}} & \multirow{2}{*}{\multicolumn{2}{|c|}{ SE }} & \multirow{2}{*}{\multicolumn{2}{|c|}{$\frac{\mathrm{DMC}_{\mathrm{a}}}{\mathrm{DMC}_{\mathrm{b}}}$}} \\
\hline & & \multicolumn{2}{|c|}{ Henke } & \multicolumn{2}{|c|}{ Keijser } & & & & & & \\
\hline & & $\mathrm{DMC}_{\mathrm{a}}$ & $\mathrm{DMC}_{\mathrm{b}}$ & $\mathrm{DMC}_{\mathrm{a}}$ & $\mathrm{DMC}_{\mathrm{b}}$ & $\left(\begin{array}{lll}1 & 1 & 0\end{array}\right)$ & $\left(\begin{array}{lll}1 & 1 & 1\end{array}\right)$ & Henke & Keijser & Henke & Keijser \\
\hline & & & & $-\mathrm{nm}$ & & & & $-\mathrm{m}^{2}$ & $\mathrm{~g}^{-1}-$ & & \\
\hline $\mathrm{PV}_{1}$ & $\begin{array}{l}\mathrm{BA} \\
\mathrm{Bt}_{3}\end{array}$ & $\begin{array}{l}61 \\
62\end{array}$ & $\begin{array}{l}44 \\
50\end{array}$ & $\begin{array}{l}55 \\
57\end{array}$ & $\begin{array}{l}34 \\
42\end{array}$ & $\begin{array}{l}0,0029 \\
0,0029\end{array}$ & $\begin{array}{l}0,0017 \\
0,0019\end{array}$ & $\begin{array}{l}19 \\
18\end{array}$ & $\begin{array}{l}23 \\
20\end{array}$ & $\begin{array}{l}1,4 \\
1,2\end{array}$ & $\begin{array}{l}1,6 \\
1,4\end{array}$ \\
\hline $\mathrm{PA}_{1}$ & $\begin{array}{l}\mathrm{BA} \\
\mathrm{Bt}_{3}\end{array}$ & $\begin{array}{l}64 \\
61\end{array}$ & $\begin{array}{l}47 \\
60\end{array}$ & $\begin{array}{l}42 \\
50\end{array}$ & $\begin{array}{l}36 \\
30\end{array}$ & $\begin{array}{l}0,0000 \\
0,0023\end{array}$ & $\begin{array}{l}0,0000 \\
0,0017\end{array}$ & $\begin{array}{l}18 \\
16\end{array}$ & $\begin{array}{l}25 \\
26\end{array}$ & $\begin{array}{l}1,4 \\
1,0\end{array}$ & $\begin{array}{l}1,1 \\
1,7\end{array}$ \\
\hline $\mathrm{PA}_{2}$ & $\begin{array}{l}\mathrm{BA} \\
\mathrm{Bt}_{3}\end{array}$ & $\begin{array}{l}63 \\
67\end{array}$ & $\begin{array}{l}61 \\
48\end{array}$ & $\begin{array}{l}46 \\
42\end{array}$ & $\begin{array}{l}33 \\
52\end{array}$ & $\begin{array}{l}0,0026 \\
0,0009\end{array}$ & $\begin{array}{l}0,0000 \\
0,0000\end{array}$ & $\begin{array}{l}16 \\
18\end{array}$ & $\begin{array}{l}26 \\
21\end{array}$ & $\begin{array}{l}1,0 \\
1,4\end{array}$ & $\begin{array}{l}1,4 \\
0,8\end{array}$ \\
\hline $\mathrm{PA}_{3}$ & $\begin{array}{l}\text { BA } \\
2 \mathrm{Cxf}_{2}\end{array}$ & $\begin{array}{l}\text { nd } \\
36\end{array}$ & $\begin{array}{l}\text { nd } \\
24\end{array}$ & $\begin{array}{l}\text { nd } \\
20\end{array}$ & $\begin{array}{l}\text { nd } \\
39\end{array}$ & $\begin{array}{c}\text { nd } \\
0,0000\end{array}$ & $\begin{array}{c}\text { nd } \\
0,0000\end{array}$ & $\begin{array}{l}\text { nd } \\
33\end{array}$ & $\begin{array}{l}\text { nd } \\
36\end{array}$ & $\begin{array}{l}\mathrm{nd} \\
1,5\end{array}$ & $\begin{array}{l}\text { nd } \\
0,5\end{array}$ \\
\hline $\mathrm{PA}_{4}$ & $\begin{array}{l}\mathrm{BA} \\
\mathrm{Bt}_{2}\end{array}$ & $\begin{array}{l}58 \\
61\end{array}$ & $\begin{array}{l}44 \\
44\end{array}$ & $\begin{array}{l}54 \\
47\end{array}$ & $\begin{array}{l}33 \\
33\end{array}$ & $\begin{array}{l}0,0030 \\
0,0027\end{array}$ & $\begin{array}{l}0,0015 \\
0,0017\end{array}$ & $\begin{array}{l}20 \\
18\end{array}$ & $\begin{array}{l}16 \\
14\end{array}$ & $\begin{array}{l}1,5 \\
1,3\end{array}$ & $\begin{array}{l}0,8 \\
0,4\end{array}$ \\
\hline $\mathrm{PV}_{2}$ & $\begin{array}{l}\mathrm{BA} \\
\mathrm{Bt}_{3}\end{array}$ & $\begin{array}{l}60 \\
62\end{array}$ & $\begin{array}{l}39 \\
48\end{array}$ & $\begin{array}{l}52 \\
54\end{array}$ & $\begin{array}{r}66 \\
120\end{array}$ & $\begin{array}{l}0,0033 \\
0,0022\end{array}$ & $\begin{array}{l}0,0019 \\
0,0009\end{array}$ & $\begin{array}{l}19 \\
19\end{array}$ & $\begin{array}{l}24 \\
24\end{array}$ & $\begin{array}{l}1,4 \\
1,4\end{array}$ & $\begin{array}{l}1,6 \\
1,6\end{array}$ \\
\hline PAC & $\begin{array}{l}\mathrm{Bhs}_{1} \\
2 \mathrm{Cx}_{2}\end{array}$ & $\begin{array}{l}\text { nd } \\
27\end{array}$ & $\begin{array}{l}\text { nd } \\
23\end{array}$ & $\begin{array}{l}\text { nd } \\
17\end{array}$ & $\begin{array}{l}\text { nd } \\
36\end{array}$ & $\begin{array}{c}\text { nd } \\
0,0000\end{array}$ & $\begin{array}{c}\text { nd } \\
0,0000\end{array}$ & $\begin{array}{l}\text { nd } \\
41\end{array}$ & $\begin{array}{l}\text { nd } \\
45\end{array}$ & $\begin{array}{l}\text { nd } \\
1,2\end{array}$ & $\begin{array}{l}\mathrm{nd} \\
0,5\end{array}$ \\
\hline $\mathrm{PA}_{5}$ & $\mathrm{Bt}_{3}$ & 53 & 39 & 38 & 40 & 0,0026 & 0,0000 & 22 & 25 & 1,3 & 0,9 \\
\hline $\mathrm{PA}_{6}$ & $\mathrm{Bt}_{2}$ & 36 & 24 & 22 & 128 & 0,0000 & 0,0000 & 33 & 26 & 1,5 & 0,2 \\
\hline $\mathrm{PA}_{7}$ & $\mathrm{Bt}_{2}$ & 58 & 42 & 37 & 44 & 0,0000 & 0,0003 & 20 & 24 & 1,4 & 0,8 \\
\hline $\mathrm{PA}_{8}$ & $\mathrm{Bt}_{2}$ & 76 & 56 & 58 & 60 & 0,0019 & 0,0007 & 15 & 17 & 1,4 & 1,0 \\
\hline $\mathrm{PA}_{9}$ & $\mathrm{Bt}_{2}$ & 42 & 30 & 29 & 23 & 0,0019 & 0,0008 & 28 & 38 & 1,4 & 1,3 \\
\hline $\mathrm{LA}_{1}$ & $\mathrm{Bt}_{2}$ & 35 & 27 & 21 & 38 & 0,0000 & 0,0000 & 33 & 37 & 1,3 & 0,6 \\
\hline
\end{tabular}

nd: não determinado em virtude da baixa definição de alguns picos do espectro de DRX.
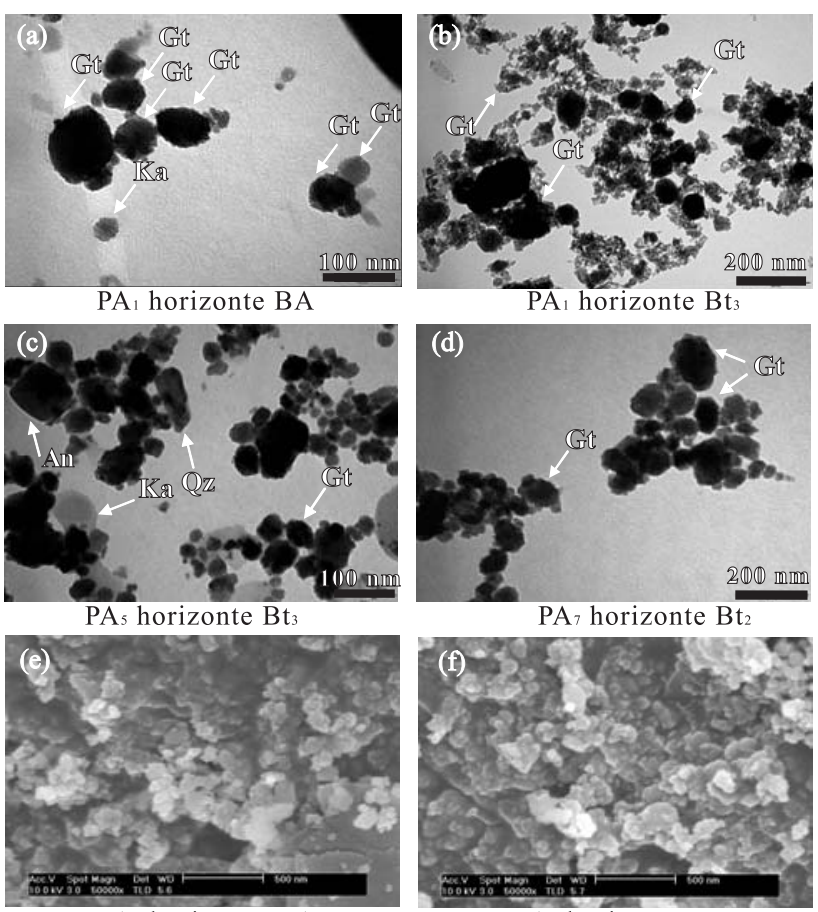

$\mathrm{PA}_{1}$ horizonte BA

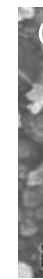

$\mathrm{PA}_{7}$ horizonte $\mathrm{Bt}_{2}$

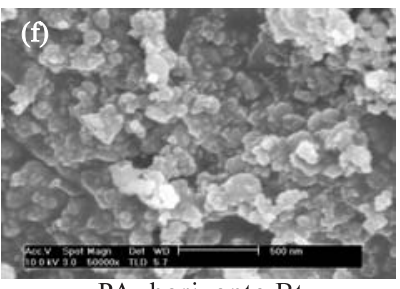

$\mathrm{PA}_{1}$ horizonte $\mathrm{Bt}_{3}$

Figura 6. Micrografias obtidas por microscopia eletrônica de transmissão (MET) (imagens de a até d) e de varredura (MEV) (imagens e e f) de concentrados de óxidos de ferro de alguns horizontes de alguns solos amarelos estudados (goethitas).
Schwertmann (1982), a $\mathrm{LMA}_{111}$ da Gt pode ser utilizada como indicativo do grau de cristalinidade do mineral, estando os menores valores associados à Gt de maior cristalinidade, com menor presença de $\mathrm{Al}$ na estrutura (menor SI). Melo et al. (2001) obtiveram significativa correlação $\left(r=0,89^{0,1} \%\right)$ entre os valores de SI e LMA LM $_{11}$ para Gt de diferentes classes de solos brasileiros. Contudo, tal correlação não foi obtida no presente trabalho.

Relação da substituição por alumínio e parâmetros cristalográficos com a posição das bandas dos espectros de ERD

Os espectros de ERD, transformados a partir da equação de Kubelka-Munk, foram ajustados por meio de seis equações gaussianas e a posição das bandas ${ }^{4} \mathrm{E}\left({ }^{4} \mathrm{D}\right),\left({ }^{4} \mathrm{E} ;{ }^{4} \mathrm{~A}_{1}\right), \mathrm{EPT}_{2}, \mathrm{EPT}_{1},{ }^{4} \mathrm{~T}_{2} \mathrm{e}^{4 \mathrm{~T}_{1}}$ foi obtida de acordo com Scheinost et al. (1999) (Figura 7).

Foi observada relação significativa entre a posição da banda ${ }^{4} \mathrm{~T}_{1}$ e a substituição isomórfica de $\mathrm{Fe}$ por $\mathrm{Al}$ nas goethitas. As partículas com maior substituição por Al apresentaram mudança para campos de menor energia (Figura 8), uma vez que a entrada do $\mathrm{Al}$ na estrutura dos hidróxidos de Fe promove alterações na ligação e na forma (menor simetria) dos octraedos $\mathrm{Fe}(\mathrm{O}, \mathrm{OH})_{6}$ (Manceau \& Combes, 1988). Resultados semelhantes foram descritos por Scheinost et al. (1999), sendo as curvas de reflectância, determinadas no presente estudo, similares às descritas pelos 
referidos autores, com pequenas variações, provavelmente, em virtude das amplitudes dos valores de substituição por Al. Foram excluídos os dados dos Espodossolos e dos solos avermelhados, por não representarem a "real" SI da goethita.

A equação linear (Figura 8) apresenta intercepto $\left(11.089 \mathrm{~cm}^{-1}\right)$ semelhante ao descrito por Scheinost et al. (1999), de $10.588 \mathrm{~cm}^{-1}$. Contudo, o parâmetro que representa a inclinação apresentou-se maior $\left(2.909 \mathrm{~cm}^{-1}\right.$ contra $\left.1.333 \mathrm{~cm}^{-1}\right)$. Tal fato é devido, possivelmente, à diferença no tamanho das partículas. Tais autores trabalharam com goethitas sintéticas, cujas dimensões

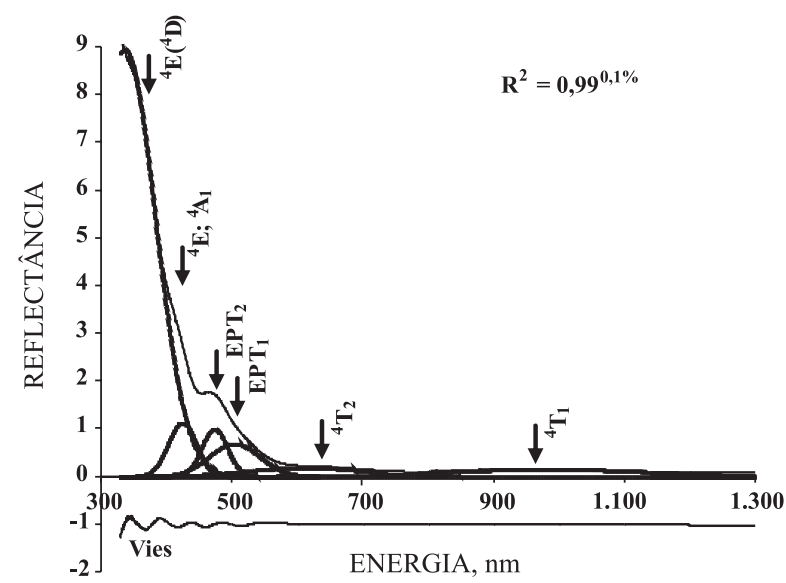

Figura 7. Deconvolução das bandas de absorção do horizonte BA do solo $\mathrm{PA}_{1}$.

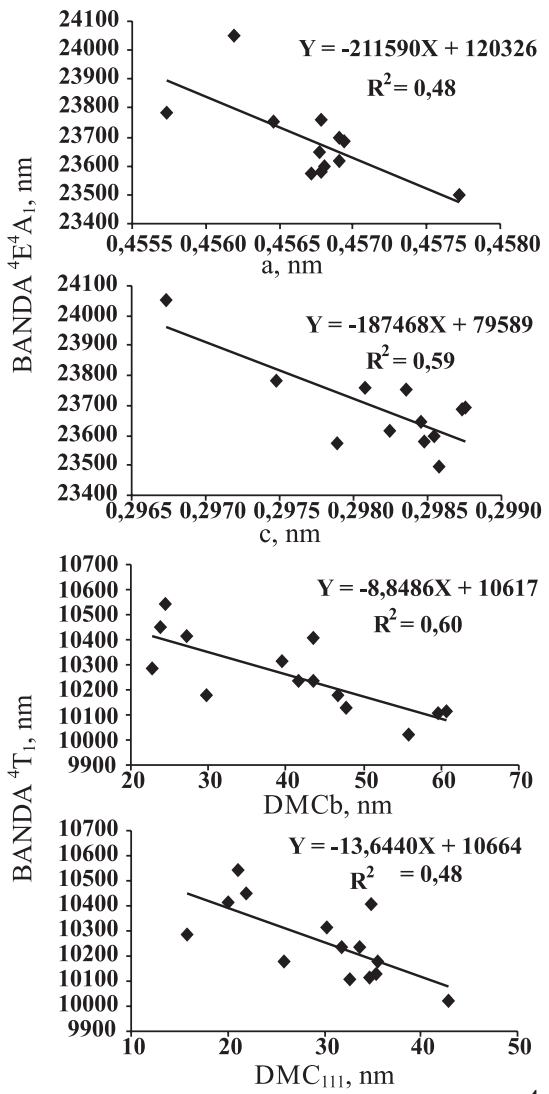

variaram de $\sim 200 \mathrm{a} \sim 1800 \mathrm{~nm}$, bem superiores às observadas no presente trabalho. Não foi verificada relação da substituição isomórfica por $\mathrm{Al}$ com a posição das outras bandas do espectro, nem com a banda ${ }^{4} \mathrm{~T}_{2}$, conforme descrito por Morris et al. (1992) e Scheinost et al. (1999).

Foram ainda observadas relações significativas entre a posição da banda ${ }^{4} \mathrm{E}^{4} \mathrm{~A}_{1}$ e as dimensões "a" $(r=$ $\left.0,70^{5 \%}\right)$, "b" $\left(r=0,76^{1 \%}\right)$ e "c" $\left(r=0,76^{1 \%}\right)$ da célula unitária, e a posição da banda ${ }^{4} \mathrm{~T}_{1}$ com os diâmetros médios do cristalito para eixos cristalográficos " $a$ " $(r$ $\left.=0,76^{1 \%}\right)$ e "b" $\left(r=0,79^{1 \%}\right)$, como também com o matiz Munsell do concentrado de Fe $\left(r=0,63^{5 \%}\right)$. Essas e outras correlações são demonstradas, em forma de regressões lineares, na figura 9 .

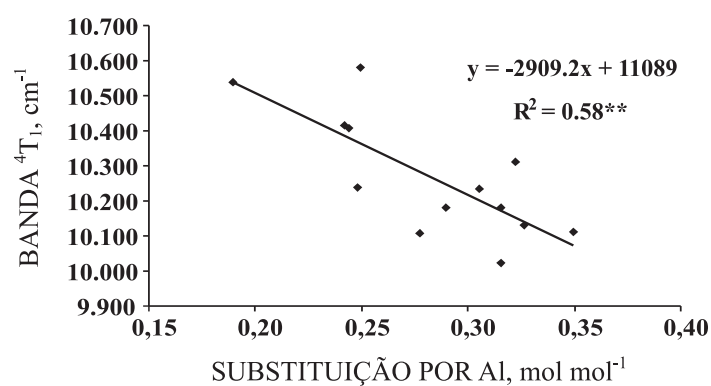

Figura 8. Relação entre a posição da banda ${ }^{4} \mathbf{T}_{1}$ (mudança para posições menos energética) e o aumento da substituição isomórfica de Fe por Al em goethitas.

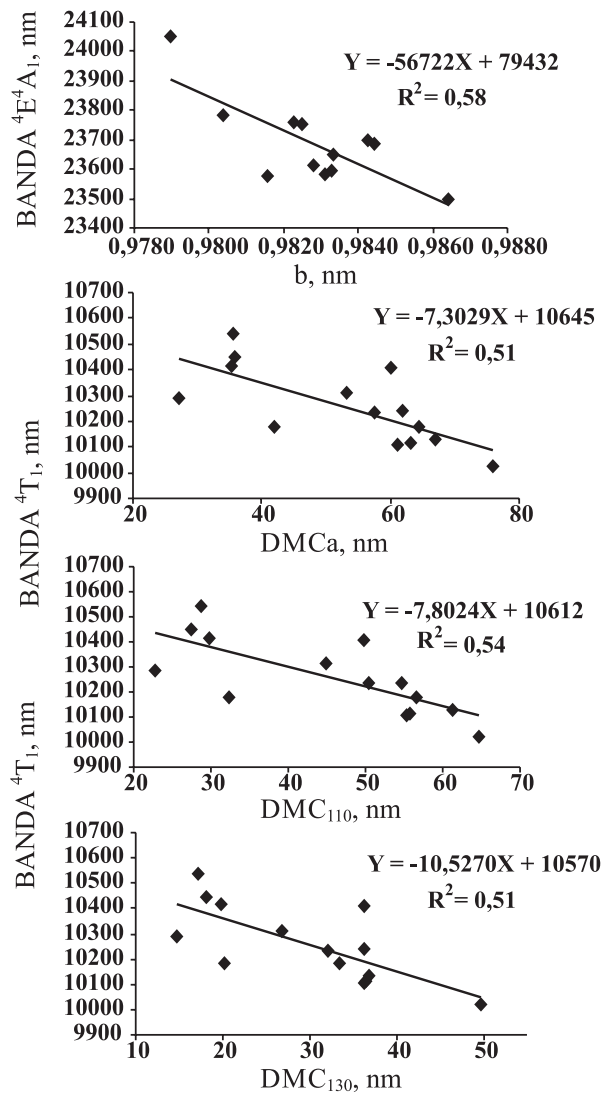

Figura 9. Relação entre a posição das bandas ${ }^{4} \mathbf{T}_{1} \mathrm{e}^{4} \mathrm{E}^{4} \mathrm{~A}_{1}$ e os parâmetros cristalográficos da goethita. 
Provavelmente, muitas dessas correlações são derivadas das alterações cristalográficas da goethita, promovidas pela presença do Al na estrutura. Seu menor raio iônico (53,5 pm), comparado com o do $\mathrm{Fe}^{+3}$ (64,5 pm), promove redução na distância entre os íons $\mathrm{Al}, \mathrm{Fe}, \mathrm{O}$ e $\mathrm{OH}$, ocorrendo, conseqüentemente, distorções dos eixos cristalográficos e octaedros, como também reduções da célula unitária e do tamanho do cristal (Schulze, 1984; Schwertmann \& Carlson, 1994).

\section{CONCLUSÕES}

1. A goethita apresentou-se como o óxido de $\mathrm{Fe}$ predominante em todos os solos, mesmo naqueles com matizes 2,5YR, cujo teor de hematita foi inferior a 2,5 dag $\mathrm{kg}^{-1}$ de argila.

2. Os valores de substituição isomórfica (SI) de Fe por $\mathrm{Al}$ das goethitas, determinados por métodos químicos, foram três a seis vezes superiores aos da hematita e não-condizentes com os valores estimados pela equação de Schulze (1984) e Schwertmann \& Carlson (1994), o que indica a necessidade de novos estudos com vistas em demonstrar as relações entre os parâmetros cristalográficos de goethitas naturais e suas propriedades químicas.

3. Os resultados obtidos por difratometria de raios X e análise de dissolução química revelaram que as goethitas dos solos estudados apresentaram alta cristalinidade, grande dimensão média do cristalito (DMC) e alto teor de $\mathrm{Al}$ estrutural.

4. A posição das bandas, obtidas nos espectros de espectroscopia de refletância difusa, apresentou correlação com algumas propriedades cristalográficas das goethitas dos solos estudados, mostrando ser uma técnica promissora no estudo dos óxidos de Fe.

\section{AGRADECIMENTOS}

À CAPES e CNPq, pelo apoio financeiro e bolsa de doutoramento "sandwich". A Aracruz Celulose, pelo apoio nos trabalhos de coleta de solos, especialmente aos doutores Sebastião Fonseca e Sebastião Andrade.

Ao Ministerio de Educación y Ciencia, Proyecto AGL2006-10927-CO3-02.

\section{LITERATURA CITADA}

BARRAL SILVA, M.T. \& RIVERA, F. Characterizacion de las goetitas de medios superficiales de Galicia y estimacion de la sustitución de Fe por Al. Cuad. Lab. Laxe, 11:115$129,1987$.
BARRÓN, V. \& TORRENT, J. Use of the Kubelka-Munk theory to study the influence of iron on soil colour. J.Soil.Sci., 37:499-510, 1986.

BOULET, R.; FRITSCH, E.; FILIZOLA, H.F.; ARAUJO FILHO, J.C.; LEPRAN, J.C.; BARRETTO, F.; BALAN, E. \& TESSIER, D. Iron bands, fragipans and duripans in the northeastern plateaus of Brazil - properties and genesis. Can. J. Soil Sci., 78:519-530, 1998.

CAGlioti, G.; PAOLETTI, A. \& RICCI, F.P. Choice of collimators for a crystal spectrometer for neutron diffraction. Nuclear Instr. Methods, 3:223-228, 1958.

CORNELL, R.M. \& SCHWERTMANN, U. The iron oxides: Structure, properties, reactions, occurence and uses. Weinheim, VHC, 1996. 573p.

CURI, N. Lithosequence and toposequence of Oxisols from Goias and Minas Gerais State, Brazil. West Lafayette, Purdue University, 1983. 158p. (Tese de Doutorado)

DEPARTAMENTO NACIONAL DE PRODUÇÃO MINERAL DNPM. Geologia do Brasil. Texto explicativo do mapa geológico do Brasil e da área oceânico adjacente, incluindo depósitos minerais. Brasília, 1984. 501p.

FERNANDES, R.B.A. Atributos mineralógicos, cor, adsorção e dessorção de fosfatos em Latossolos do sudeste brasileiro. Viçosa, MG, Universidade Federal de Viçosa, 2000. 265p. (Tese de Doutorado)

FEY, M.V. \& DIXON, J.B. Synthesis and properties of poorly crystalline hydrated aluminous goethites. Clays Clay Miner., 29:91-100, 1981.

FEY, M.V. \& le ROUX, J. Properties and quantitative estimation of poorly crystalline components in sesquioxidic soil clays. Clays Clay Miner., 25:285-294, 1977.

FITZPATRICK, R.W. \& SCHWERTMANN, U. Al-substituted goethite - an indicator of pedogenic and other weathering environments in South Africa. Geoderma, 27:335-347, 1982.

FONTES, M.P.F. Iron oxide mineralogy in some brazilian Oxisols. Raleigh, North Carolina State University, 1988. 175p. (Tese de Doutorado)

FONTES, M.P.F. \& WEED, S.B. Iron oxides in selected brazilian Oxisols: I. Mineralogy. Soil Sci. Soc. Am. J., 55:1143-1149, 1991.

HENKE, B.L.; PERERA, R.C.C.; GULLIKSON, E.M. \& SCHATTENBURG, M.L. High-efficiency low-energy $\mathrm{x}$ ray spectroscopy in the $100-500-\mathrm{eV}$ region. J. Appl. Phys., 49:480-494, 1978.

HUNTER, B.A. \& HOWARD, C.J. A computer program for Rietveld analysis of $\mathrm{x}$-ray an neutron power diffraction patterns. New Illawarra Road, Australian Nuclear Science and Tecnology Organization, 2000. 27p.

KÄMPF, N. \& SCHWERTMANN, U. The $5 \mathrm{M} \mathrm{NaOH}$ concentrations treatment for iron oxides in soils. Clays Clay Miner., 23:310-317, 1982.

KEIJSER, TH.H.; MITTMEIJER, E.J. \& ROZENDAAL, C.F. The determination of crystallite-size and lattice-strain parameters in conjunction with the profile-refinament method for determination of crystal structures. J. Appl. Cryst., 16:309-316, 1983. 
KER, J.C. Mineralogia, sorção e dessorção de fosfatos, magnetização e elementos traços de Latossolos do Brasil. Viçosa, MG, Universidade Federal de Viçosa, 1995. 181p. (Tese de Doutorado)

KOSMAS, C.S.; CURI, N.; BRYANT, R.B. \& FRANZMEIER, D.P. Characterization of iron oxides minerals by secondderivate visible spectroscopy. Soil Sci. Soc. Am. J., 48:401405, 1984.

MANCEAU, A. \& COMBES, J.M. Structure of Mn and Fe oxides and oxyhydroxides. A topological approach by EXAFS. Phys. Chem. Miner., 15:283-295, 1988.

MEHRA, J.P. \& JACKSON, M.L. Iron oxides removal from soils and clays by a dithionite-citrate-bicarbonate system buffered with bicarbonate sodium. Clay Clay Miner., 7:317-327, 1960 .

MELO, V.F.; FONTES, M.P.F.; NOVAIS, R.F.; SINGH, B. \& SCHAEFER, C.E.G.R. Caracterização dos óxidos de ferro e de alumínio de diferentes classes de solos. R. Bras. Ci. Solo., 25:19-32, 2001.

MOREAU, A.M.S.S. Gênese, química e micromorfologia de horizontes coeso, fragipã e duripã em solos do tabuleiro costeiro no sul da Bahia. Viçosa, MG, Universidade Federal de Viçosa, 2001. 139p. (Tese de Doutorado)

MORRIS, R.V.; SCHULZE, D.G.; LAUER, H.V.; AGRESTI, D.G. \& SHELFER, T.D. Reflectivity (visuble and near IR), Möussbauer, static magnetic and x-ray difractind properties of Al-substituted hematites. J. Geophys. Res., 97:10257-10266, 1992.

MOURA FILHO, G.; RESENDE, M. \& CRUZ, C.D. ALOCA Programa de estimativa de minerais do solo. Versão 1.0 In: CONGRESSO BRASILEIRO DE CIÊNCIA DO SOLO, 25., Viçosa, 1995. Viçosa, MG, Sociedade Brasileira de Ciência do Solo, 1995 (Software).

RESENDE, M. Mineralogy, chemistry, morphology and geomorphology of some soils of Central Plateau of Brazil. West Lafayette, Purdue University, 1976. 237p. (Tese de Doutorado)

RIETVELD, H.M. A profile refinament method for nuclear and magnetic structures. J. Appl. Cryst., 2:65-71, 1969.

SCHEINOST, A.C.; CHAVERNAS, A.; BARRON, V. \& TORRENT, J. Use and limitations of second-derivative diffuse reflectance spectroscopy in the visible to nearinfrared range to identify and quantify Fe oxides in soils. Clays Clay Miner., 46:528-536, 1998.
SCHEINOST, A.C.; SCHULZE, D.G. \& SCHWERTMWNN, U. Diffuse reflectance spectra of Al substituted goethite: A ligand field approach. Clays Clay Miner., 47:156-164, 1999.

SCHULZE, D.G. The Influence of aluminum on iron oxides. VIII. Unit-cell dimensions of $\mathrm{Al}$-substituted goethites and estimation of $\mathrm{Al}$ from them. Clays Clay Miner., 32:36$44,1984$.

SCHWERTMANN, U. Ocorrence and formation of iron oxides in various pedoenvironments. In: STUCKI, J.W.; GOODMAN, B.A. \& SCWERTMANN, U., eds. Iron in soils and clays minerals. Proceeding. Dordrecht, 1988. p. 267-308. (NATO ASI Series, 217)

SCHWERTMANN, U. Use of oxalate for Fe extraction from soil. Can. J. Soil Sci., 53:244-248, 1973.

SCHWERTMANN, U. \& CARLSON, L. Aluminum influence on iron oxides: XVII. Unit-cell parameters and aluminum substitution of natural goethites. Soil Sci. Soc. Am. J., 58:256-261, 1994.

SCHWERTMANN, U. \& TAYLOR, R.M. Iron oxides. In: DIXON, J.B. \& WEED, S.B., eds. Minerals in soil environments. Madison, Soil Science Society of America, 1989. p.379-438.

SCHWERTMANN, U.; FITPATRICK, R.W.; TAYLOR, R.M. \& LEWIS, D.G. The influence of aluminun on iron oxides. Part II. Preparation and properties of Al-substituted hematite. Clays Clay Miner., 27:105-112, 1979.

SILVA, J.M.R.; LIMA, M.I.C.; VERONESE, V.F.; RIBEIRO JÚNIOR, R.N.; ROCHA, R.M. \& SIGA JUNIOR, O. Secretaria de Planejamento e Coordenação da Presidência da República - Fundação Instituto Brasileiro de Geografia e Estatística - IBGE. Geologia. . Folha SE.24 Rio Doce. Rio de Janeiro, 1987. p.23-172. (Levantamento de Recursos Naturais, 34)

SIQUEIRA, J.D.P.; LISBOA, R.S.; FERREIRA, A.M.; SOUZA, M.F.R.; ARAÚJO, E.; LISBÃO JÚNIOR, L. \& SIQUEIRA, M.M. Estudo ambiental para os programas de fomanto florestal da Aracruz Celulose S.A. e extensão florestal do Governo do Estado do Espírito Santo. Floresta, Edição Especial, 3-67, 2004.

THIEL, R. Zum system a-FeOOH-a-AlOOH. Z. Anorg. Allg. Chem., v.326, p.70-78, 1963.

TORRENT, J.; SCHWERTMANN, U. \& BARRÓN, V. The redutive dissolution of synthetic goethite and hematite in dithionite. Clay Miner., 329-337, 1987. 